\title{
Cerebellar Nucleo-Olivary Projections in the Rat: An Anterograde Tracing Study With Phaseolus vulgaris-Leucoagglutinin (PHA-L)
}

\author{
T.J.H. RUTGROK AND J. VOOGD \\ Department of Anatomy, Erasmus University, 6000 DR Rotterdam, The Netherlands
}

\begin{abstract}
In order to evaluate the reciprocity of olivo-cerebellar and cerebello-olivary connections, a detailed description of the cerebellar nucleo-olivary projection in the rat is presented using small, iontophoretic injections of the anterograde tracer Phaseolus vulgaris-leucoagglutinin.

Sparse projections were found to arise from the rostral part of the medial cerebellar nucleus toward the lateral part of the caudal medial accessory olive. Its medial parts receive a projection from the dorsolateral protuberance of the medial cerebellar nucleus. Caudal and lateral regions of the medial cerebellar nucleus project to the "beta" group and dorsomedial cell column.

Heavy olivary projections to circumscribed parts of the inferior olive were found after injections in the remaining cerebellar nuclei. The medial part of the posterior interposed nucleus connects to caudolateral areas of the rostral half of the medial accessory olive, whereas lateral areas project to more rostromedial parts. The most ventromedial part of the lateral cerebellar nucleus projects to the ventrolateral outgrowth. Adjacent medial, ventral, and caudal regions connect to the ventral leaf of the principal olive. The cerebellar origin of the projection to its dorsal leaf is located in lateral, dorsal, and rostral parts of the lateral cerebellar nucleus. The dorsolateral hump projects to the dorsomedial group of the rat inferior olive. Rostromedial projections to the dorsal accessory olive originate from the lateral part of the anterior interposed nucleus, whereas its medial parts project to more lateral and caudal regions of this olivary subnucleus. The dorsal fold of the dorsal accessory olive does not receive a projection from the cerebellar nuclei but from the lateral vestibular nucleus. No cerebellar projections were found to the dorsal cap. Relatively strong ipsilateral projections, which were the mirror images of the contralateral projections, were observed in the dorsomedial group, rostral medial accessory olive, and ventral leaf of the principal olive.

When both the inferior olive and the cerebellar nuclei are considered as folded but continuous sheets of grey matter, the complete nucleo-olivary projection can be described as a simple transformation.
\end{abstract}

Key words: cerebellum, cerebellar nuclei, inferior olive, GABA, fiber course

It has been well established that the olivo-cerebellar projection is rigidly organized, establishing connections with parasagittal strips of Purkinje cells and circumscript areas of the cerebellar nuclei (e.g., Groenewegen and Voogd, '77; Groenewegen et al., '79; Brodal and Kawamura, '80; Arends and Voogd, '89; Billard et al., '89; Van der Want et al., '89). The reverse cerebellar nucleo-olivary projection has been described in various mammalian species, like the oppossum (Dom et al., '73), the rat (Angaut and Cicirata, '82), the cat (Graybiel et al., '73), and the monkey (ChanPalay, '77). In the cat, it has been demonstrated that the olivo-nuclear and nucleo-olivary projections are reciprocally organized (Beitz, '76; Dietrichs and Walberg, '85, '86, '89; Dietrichs et al., '85). The existence of reciprocal connections has also been suggested for other animal species (see Brodal and Kawamura, ' 80 for review). Thus the dentate nucleus would be reciprocally connected with the principal olive, whereas the interposed nuclei are connected with the accessory nuclei. Whether the medial cerebellar nucleus

\section{Accepted May 10, 1990}

Address reprint requests to Dr. T.J.H. Ruigrok, Dept. of Anatomy, Medical Faculty, Erasmus University Rotterdam, P.O. Box 1738, 3000 DR Rotterdam, The Netherlands. 
(MCN) projects to any part of the inferior olivary complex is still disputed. In the rat, such a projection was denied by Brown et al. ('77) and Haroian ('82), but was found by Achenbach and Goodman ('68), Angaut and Cicirata ('82), Swenson and Castro ('83a,b), and by Buisseret-Delmas et al. ('89) for the most ventral part of the MCN.

A rather precise relation between the dentate nucleus and the principal olive was shown in man (Lapresle and Ben Hamida, '70) and monkey (Chan-Palay, '77; Kalil, '79). Similar relationships have been suggested for the rat and cat, though here conclusions from different authors and for different species are not compatible. Detailed relationships between parts of the interposed nuclei and the accessory olivary nuclei have been reported only in the cat (Courville et al., '83; Dietrichs and Walberg, '86).

Recently, an anterograde tracer, Phaseolus vulgaris. leucoagglutinin (PHA-L), has become available, which makes it possible to place small, localized, iontophoretic injections into selected brain areas (Gerfen and Sawchencko, '84). We used this technique to study the nucleo-olivary projection in the rat in considerable detail. Special attention was paid to: (1) the fastigio-olivary projection, (2) the relation between parts of the cerebellar nuclei and the inferior olive, (3) the presence of ipsilateral olivary projections, (4) the relative density of the nucleo-olivary labelling, and (5) the course of the nucleo-olivary fibers.

\section{MATERIALS AND METHODS Surgical procedure}

A total of 29 adult male Wistar rats (200-250 gm) was used for this study. They were anaesthetized with pentobarbital (Nembutal, $120 \mathrm{mg} / \mathrm{kg}$, i.p.). Following mounting in a stereotactic device, the squamosal part of the occipital bone was freed of neck muscles and the foramen magnum was enlarged. From a horizontal approach, a stereotactic (Paxinos and Watson, '86) injection into a selected area of the cerebellar nuclei (usually on the right side) was made with a glass micropipette (tip diameter 8-15 $\mu \mathrm{m}$ ), backfilled with a $2.5 \%$ PHA-L (Vector) solution in $0.05 \mathrm{M}$ Tris-buffered saline solution ( $\mathrm{pH} 7.4$ ). The tracer was injected iontophoretically by means of a positive current (which was constantly monitored) of 4 to $8 \mu \mathrm{A}$, pulsed $7 \mathrm{sec}$ on, $7 \mathrm{sec}$ off, for a total of 15-30 minutes. Afterward, the pipette was withdrawn, the wound sutured, and the animal allowed to recover.

\section{Histochemical procedure}

After a survival time of 5 to 8 days, the animals were deeply anaesthetized with an overdose of pentobarbital (Nembutal, $200 \mathrm{mg} / \mathrm{kg}$ ), and perfusion fixed according to the following protocol. Blood was rinsed out with a $0.05 \mathrm{M}$ phosphate buffer ( $\mathrm{pH} 7.4$ ) containing $0.8 \% \mathrm{NaCl}, 0.8 \%$ sucrose, and $0.4 \%$ d-glucose $(100-200 \mathrm{ml})$; this was followed by $1,000 \mathrm{ml}$ fixative consisting of $0.5 \%$ paraformaldehyde, $2.5 \%$ glutaraldehyde, and $4 \%$ sucrose in the same buffer. Dissected brains were kept in the same fixative for 2-4 hours, transferred to a $10 \%$ sucrose solution in phosphate buffer until they sank, and embedded in $10 \%$ gelatin (dissolved in the same sucrose-buffer solution). The gelatin was hardened in $4 \%$ paraformaldehyde (also dissolved in the same sucrose-buffer solution) for 3 hours. Finally, the embedded brains were transferred to a $30 \%$ sucrose solution in phosphate buffer where they were stored (at $4^{\circ} \mathrm{C}$ ) until they sank.

Transverse sections $(40 \mu \mathrm{m})$ of the cerebellum and lower brainstem were cut on a freezing microtome. Serial sections were collected in small glass vials in Tris-buffered saline (TBS: $0.9 \% \mathrm{NaCl}$ in $0.05 \mathrm{M}$ Tris-HCl, $\mathrm{pH} 7.4$ ). The sections were rinsed in TBS $(3 \times 15 \mathrm{~min})$ and incubated overnight in the primary antiserum (goat anti-PHA-L, Vector) diluted $1 / 2,000$ in Tris-buffered saline containing Triton X-100 (TBS+: $0.5 \mathrm{M} \mathrm{NaCl}, 0.2-0.4 \%$ Triton X-100 in $0.05 \mathrm{M}$ Tris-HCl, $\mathrm{pH}$ 8.6). Subsequently, sections were rinsed in TBS + $(3 \times 15 \mathrm{~min})$, incubated for 2 hours in rabbitantigoat IgG (Sigma, 1/200 in TBS+), again rinsed in TBS+ $(3 \times 15 \mathrm{~min}$ ) incubated for 2 hours in goat PAP (Nordic, $1 / 400$ in TBS +). Finally, sections were thoroughly rinsed in Tris-HCl (0.05 M, pH 7.6) and incubated with $0.05 \%$ DAB (3,3-diaminobenzidine-tetrahydrochloride, Sigma) and $0.01 \% \mathrm{H} 2 \mathrm{O} 2$ in Tris- $\mathrm{HCl}$ for $30-45$ minutes. Following thorough rinsing in Tris- $\mathrm{HCl}$, sections were mounted on chrome-gelatinized slides, air dried, counterstained with either cresyl violet or neutral red, and coverslipped with Permount.

\section{Analysis of injections and projections}

The injection sites were indicated on a series of 11 standardized transverse diagrams of the cerebellar nuclei, taken at $160-\mu \mathrm{m}$ intervals (Fig. 1). Terminology was adapted from Korneliussen ('68) and Voogd et al. ('85). Basically,

Abbreviations

\begin{tabular}{|c|c|}
\hline AIN & anterior interposed nucleus \\
\hline CMCN & caudomedial subdivision of $\mathrm{MCN}$ \\
\hline $\mathrm{Co}$ & cochlear nuclei \\
\hline DAO & dorsal accessory olive \\
\hline das & dorsal acoustic stria \\
\hline DC & dorsal cap \\
\hline DLH & dorsolateral hump \\
\hline DLP & dorsolateral protuberance \\
\hline DLPO & dorsal leaf of principal olive \\
\hline DM & dorsomedial group \\
\hline DMC & dorsomedial crest \\
\hline DMCC & dorsomedial cell column \\
\hline GABA & gamma-amino butyric acid \\
\hline GAD & glutamic acid decarboxylase \\
\hline icp & inferior cerebellar peduncle \\
\hline LCN & lateral cerebellar nucleus \\
\hline$L V, L V N$ & lateral vestibular nucleus \\
\hline $\mathrm{MAO}$ & medial accessory olive \\
\hline $\mathrm{MCN}$ & medial cerebellar nucleus \\
\hline mcp & medial cerebellar peduncle \\
\hline
\end{tabular}

ml
MMCN
MV
$7 n$
PH
PHA-L
PIN
PO
py
scp
Sp5
SpV
SuV
unc
VLO
VLPO
8vn
WGA-BSA
WGA-HRP
Y

medial lemniscus

middle subdivision of $\mathrm{MCN}$

medial vestibular nucleus

facial nerve

prepositus hypoglossal nucleus

Phaseolus vulgaris-leucoagghtinin

posterior interposed nucleus

principal olive

pyramidal tract

superior cerebellar peduncle

spinal trigeminal tract

spinal vestibular nucleus

superior vestibular nucleus

uncinate tract

ventrolateral outgrowth

ventral leaf of principal olive

vestibular nerve

wheatgerm agglutinate conjugated bovineserum albumin

wheatgerm agglutinate conjugated horseradish peroxidase $y$-nucleus 

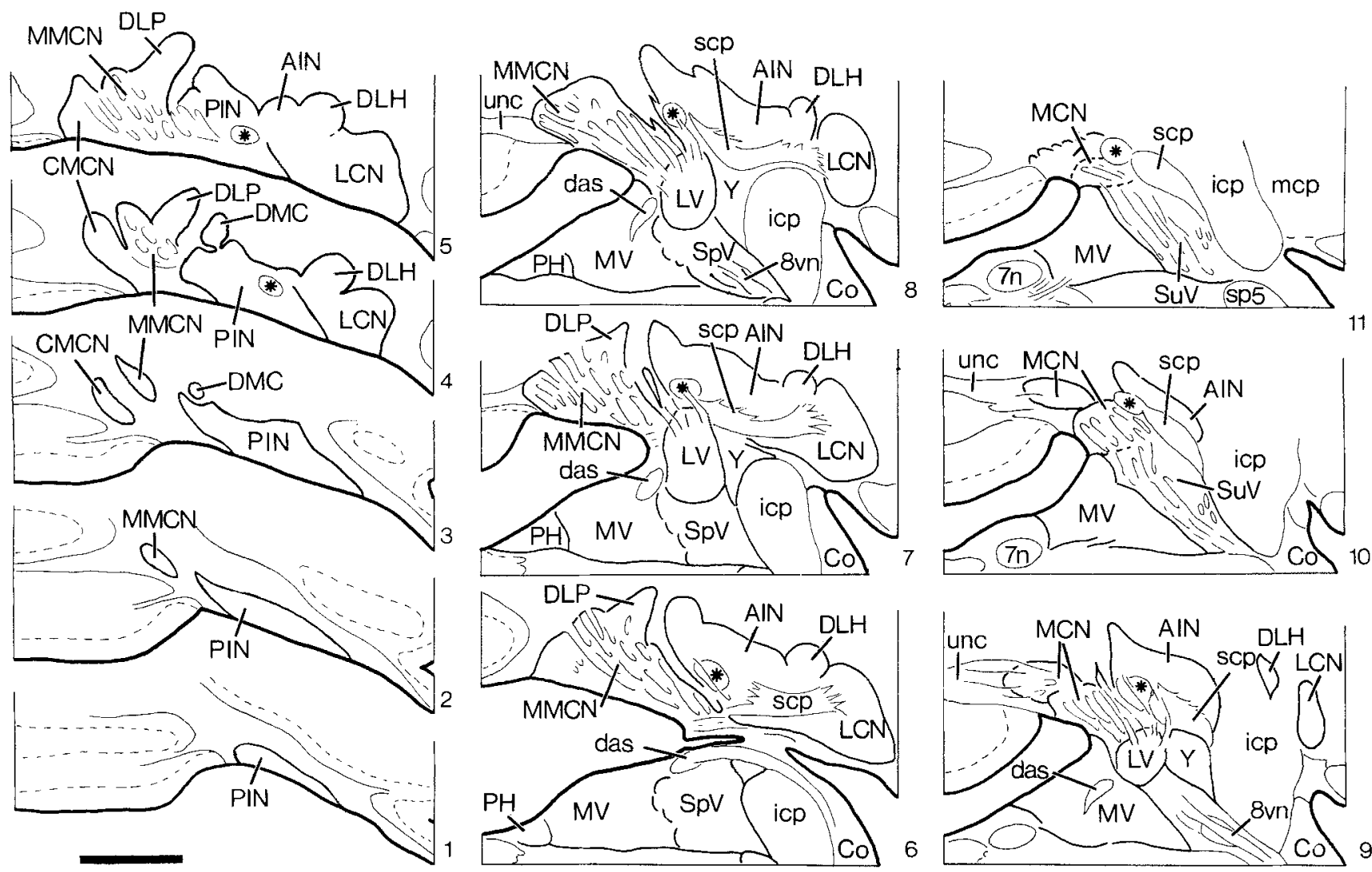

Fig. 1. Diagrammatic representation of the rat cerebellar nuclei (of the right side), based on coronal sections spaced $160 \mu \mathrm{m}$. Midline is to the left-hand side. Caudal is at bottom far left (1), rostral is at top far right (11). Bar equals $1.0 \mathrm{~mm} .{ }^{*}$ : part of scp arising from PIN.

four distinct cerebellar nuclei can be recognized; a medial cerebellar nucleus (MCN), a posterior interposed nucleus (PIN), an anterior interposed nucleus (AIN), and a lateral cerebellar nucleus (LCN). Characteristic features of the rat cerebellar mass are: the dorsolateral hump (DLH), which lies intercalated between the interposed nuclei and the LCN, the dorsolateral protuberance (DLP) of the MCN, and the dorsomedial crest (DMC) which is judged to be a caudomedial extension of the medial part of the AIN (Goodman et al., '63; Korneliussen, '68; Voogd et al., '85).

Projections were plotted in standardized, transverse diagrams of the inferior olive also spaced at $160 \mu \mathrm{m}$ (Fig. 2A). The terminology used for the inferior olive is essentially similar to the one described by Bernard ('87), although, unlike this author but in accordance with Azizi and Woodward ('87), we recognized a caudally positioned dorsal fold of the dorsal accessory olive (DAO). In order to enhance visibility of projection patterns, we also made use of a diagram of the unfolded olive (Fig. 2B,C), similar to Brodal's ('40) diagram of the inferior olive of the cat. In the rat, however, the whole olivary complex is presented as one continuous sheet of cells.

\section{RESULTS}

The iontophoretic injections of PHA-L appear as rather small (diameter approx. 400-500 $\mu \mathrm{m}$ ), darkly brownstained, round or oval shape areas that contain numerous darkly stained cell bodies. Sometimes, this area was posi- tioned within a larger (diam. up to $800 \mu \mathrm{m}$ ) area of light to moderately brown staining in which no immunoreactive cell bodies could be discerned. As described in a recent paper by Van der Want et al. ('89), the effective injection site appears to be confined to the area of dark brown staining (see also Gerfen and Sawchencko, '84; Wouterlood and Groenewegen, '85). Some of the experiments reported below also contain an injection of a gold-labelled wheatgerm agglutinate-bovine serum albumin conjugate (WGA-BSA) into the contralateral inferior olivary complex (Ruigrok and Voogd, '88a). However, these injections did not disturb, influence, or conceal the cerebellar nucleo-olivary projection pattern.

PHA-L anterograde tracing results in a complete and detailed labelling of preterminal and terminal fibers that show varicosities and intervaricose segments. This allows a precise investigation of the morphological appearance and the topological aspects of axonal projection patterns (Gerfen and Sawchencko, '84; Van der Want et al., '89).

The number of labelled varicosities per sectional surface area was used as a measure of the density of the projection and was subjectively scaled as sparse, moderate, or high.

\section{Injections centered on the medial cerebellar nucleus (MCN)}

The MCN can be subdivided into three subgroups (Korneliussen, '68; Voogd et al., ' 85 ). The caudomedial subdivision (CMCN) is located at the base of the nodule and uvula. 

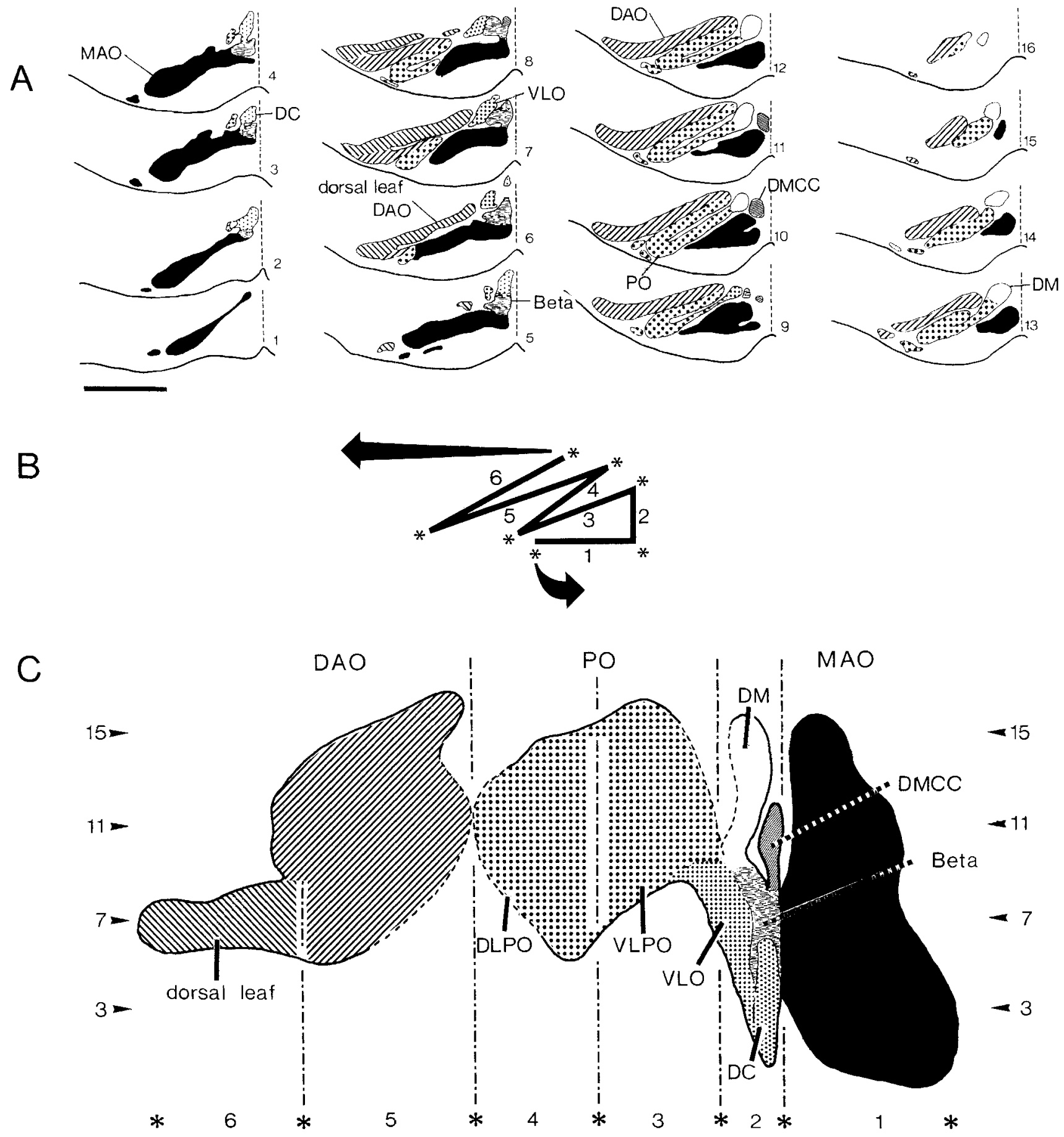

Fig. 2. A. Diagrammatic representation of the rat inferior olive based on coronal sections, spaced $160 \mu \mathrm{m}$. Caudal is at bottom far left (1), rostral is at top far right (16), Bar equals $100 \mu \mathrm{m}$. B,C: Diagram. matic representation of the rat inferior olive as an unfolded, stretched-

out sheet of cells. The principle of unfolding is schematically shown in B. Numbers at the left- and right-hand side in $C$ correspond to the different rostrocaudal levels depicted in A. Symbols in $\mathrm{C}$ also correspond to symbols used in A. See text for further explanation.

Dorsally and ventrolaterally it borders to the middle subdivision (MMCN), which is distinguished by its high content of myelinated fibers. The dorsolateral protuberance (DLP) stands rather isolated within the white matter of the posterior lobe. Rostrally, the MMCN and the DLP appear to be continuous.

The description of the olivary projection from the MCN is based on 10 experiments. All injections were judged to be within the limits of this nucleus. PHA-L labelled fibers left the cerebellum via the uncinate tract from where they entered the vestibular nuclei and reticular formation. A variable, though smaller, contigent of fibers left the cerebel- 
lum ipsilaterally through the superior cerebellar peduncle (scp). Since all MCN injections resulted in heavy labelling of fibers in the contralateral paramedian reticular formation immediately dorsal and rostral of the inferior olive, it was not possible to determine the course of the olivary-directed fibers.

The results of six injections are shown in Figure 3, all demonstrating a projection to the inferior olive. Case R142 was centered on the rostral half of the MMCN, whereas case $R 143$ covered more caudal areas including the CMCN. The injection in case R219 was located ventrally in caudal areas but shifted to a more dorsal position rostrally (see also Fig. 4A). Two injections (R127 and R128) were limited to the DLP. In another case (R149) the injection was positioned ventrolaterally within the MCN.

The rostral MCN injection in case R142 (Fig. 3B,C) and in case R218 (not shown) resulted in terminal labelling of moderate density in the most lateral parts of the caudal MAO. The CMCN injection in case R143 resulted in anterograde labelling of moderate density exclusively within group "beta." In fact, the rostral boundary of the projection demarcated rather sharply the border between this group and the nonlabelled VLO. Case R219, showing some overlap of its injection site with the former two cases, resulted in labelling in both the lateral part of the caudal MAO and in group "beta" (Fig. 4B). Three other cases (R100, R130, $\mathrm{R} 217$, not shown) also resulted, to different degrees, in labelling of both areas.

The injection site of case R149 involved the ventrolateralmost aspects of the MCN (Fig. 3). It resulted in labelling of the lateral and central aspects of the contralateral, caudal MAO, but also showed a sparse terminal labelling within the DMCC on both sides.

The injections into the DLP (cases R127 and R128) resulted in patterns of terminal arborizations of moderate density that were found within the medial part of the caudal MAO. In case R127, with a more lateral injection, this area was located slightly rostral and medial to the one in case R128, with a more medial injection (Fig. 3 ).

Because none of the above mentioned injections were centered exclusively within the CMCN or MMCN and because the borders between these two subnuclei are rather vague ventrally and rostrally, it was not possible to determine to what extent they project to different areas of the inferior olive. Based on our observations, it was concluded that lateral parts of the caudal MAO receive a projection from the rostral MCN. The DLP is connected to medial aspects of the caudal MAO (not to group "beta"). The caudal and lateral MCN provide an input to the "beta" group, whereas the DMCC is labelled from a ventrolateral part of the MCN.

\section{Injections centered on the posterior interposed nucleus (PIN)}

In the rat the PIN was described as the smallest of the cerebellar nuclei, containing rather large cells, although a distinct area with smaller cells can be recognized ventromedially (Korneliussen, '68; Voogd et al., '85). Projections of the PIN could be evaluated in a total of five cases. Three cases are shown here (Fig. 5A); a medial injection in R14, a lateral injection in R97, which also involved the ventromedial part of the caudal LCN (see also Fig. 6A), and R99, which involved the medial PIN, together with the medial part of the AIN (especially the dorsomedial crest: DMC) and touching upon the DLP. Two other cases were mainly centered on the AIN (R18) and the LCN (R177, see Fig. 7).

Small to medium-size (diam. $<4 \mu \mathrm{m}$ ) labelled fibers left the cerebellum through the ipsilateral scp (Fig. 6B), taking up positions described earlier by Haroian et al. ('81). Some fibers could also be observed in the contralateral scp (Fig. 6C). After crossing within the decussation of the scp, rather thin fibers (diam. $<2 \mu \mathrm{m}$ ) entered the crossed descending limb of the scp. Caudal to the pontine nuclei only thin caliber fibers (diam. $<1.5 \mu \mathrm{m}$ ) were found, descending as a loosely packed bundle located directly dorsal to the intermediate and lateral parts of the pyramidal tract (Fig. 6D), from where they entered the olivary nuclear complex.

The medial injections in cases R14 and R99 resulted in a dense terminal labelling within the caudal part of the rostral half of the MAO. Case R99 showed labelling at more caudolateral areas of the rostral MAO, but also in a small, isolated, patch medially, which is most likely due to the involvement of the DLP. In this case, an additional projection was found in the caudolateral part of the DAO. High density terminal labelling was found in almost the whole rostral half of the MAO in case $R 97$, together with labelling within the VLPO (Fig. 5). The labelling outside the rostral $\mathrm{MAO}$, in the DAO in case R99 can be explained by the extension of the injection site into the DMC and the medial part of the AIN. The labelling of the VLPO in case R97 is due to the inclusion of the medial LCN in the injection site. The projections from the MCN and the PIN to the caudal and rostral MAO, respectively, appear to be completely segregated. The overlap, suggested by the diagrams of the unfolded olive, in cases R127 (Fig. 3B) and R14 (Fig. 5B), with injections centered upon the DLP and the PIN, respectively, is due to their location at different dorsoventral levels of the MAO.

Based on these results, we assume that the PIN, as far as the projection to the inferior olive is concerned, only projects to the rostral half of the MAO. The rostromedial parts of the PIN are connected with caudolateral levels of the rostral MAO, more caudolateral parts rather project to more rostromedial levels of the rostral MAO. The results of cases R18 (not shown) and R177 (Fig. 7) are compatible with this notion.

\section{Injections centered on the lateral cerebellar nucleus (LCN)}

Four injection sites (cases R96, R131, R132, R133; Fig. 7A) are described here, which were confined within the borders of the LCN. Four additional cases also involved the PIN (R97, Fig. 5A; R177, Fig. 7A), the lateral part of the AIN (case R24, Fig. 8A), and the AIN and the ' $\mathrm{Y}$ ' nucleus (R182, Fig. 7A, see also Fig. 6F).

Virtually all labelled fibers left the cerebellum through the ipsilateral scp, where they occupied a ventrolateral position (Haroian et al., ' 81 ). Following a course described earlier for PIN fibers, they entered the olive from positions directly dorsal to the lateral part of the pyramidal tract.

All injections involving the LCN resulted in high density terminal labelling within the $\mathrm{PO}$. The injection site in case R133 covered the caudomedial aspects of the LCN (Fig. 7A). It resulted in labelling of the ventral leaf of the principal olive (VLPO) at rostral levels (Fig. $7 \mathrm{~B}, \mathrm{C}$ ), not unlike the VLPO labelling in cases R97 (Fig. 5B,C) and R24 (Fig. $8 \mathrm{~B}, \mathrm{C}$ ) with injection sites extending into caudomedial LCN from PIN and AIN, respectively. When the injection site was situated more ventrally in the caudal LCN, as in case 
A ${ }^{128}$
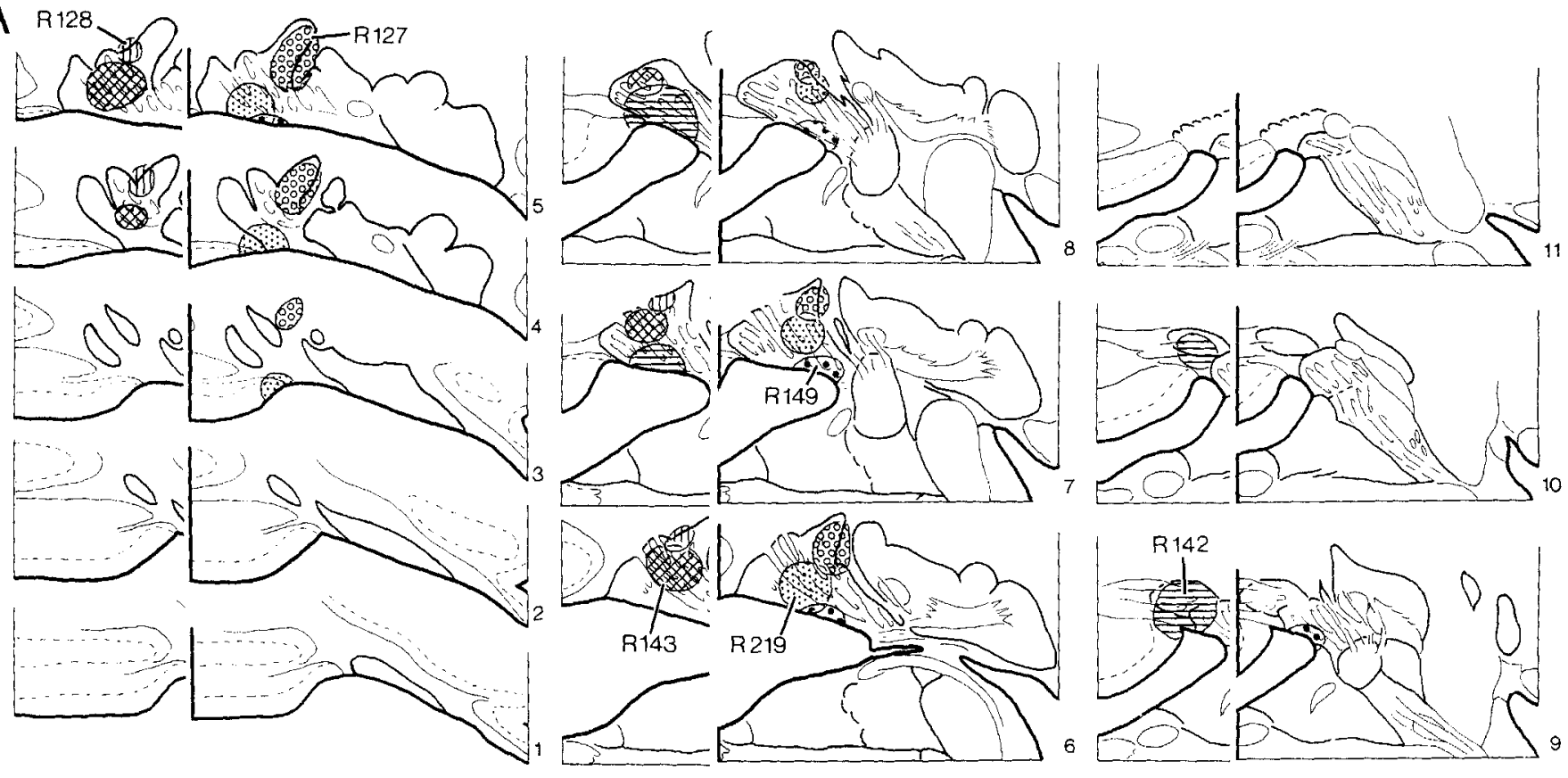

B

R 128

R 142

R 143
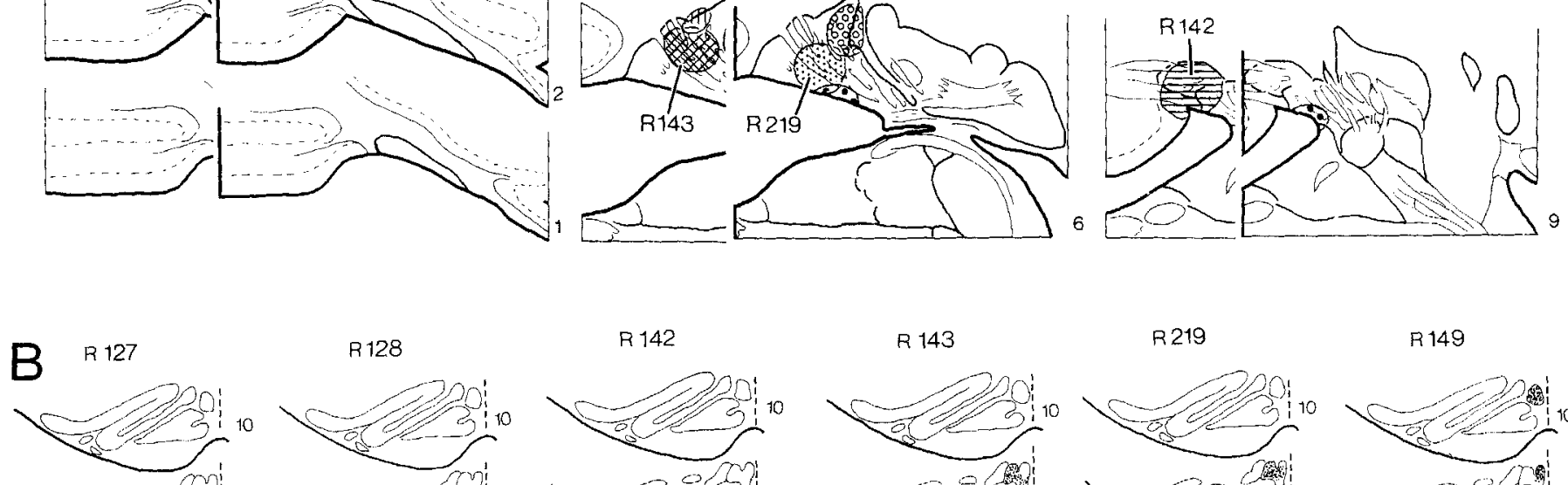

${ }_{020}{ }_{8}$
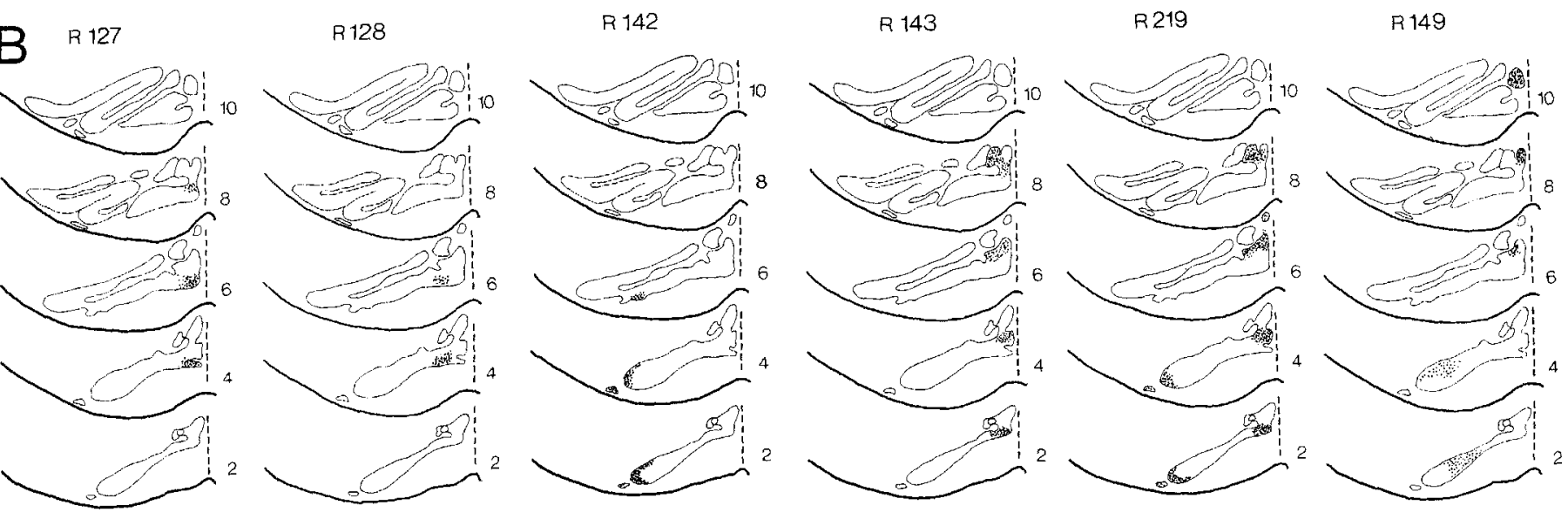

C

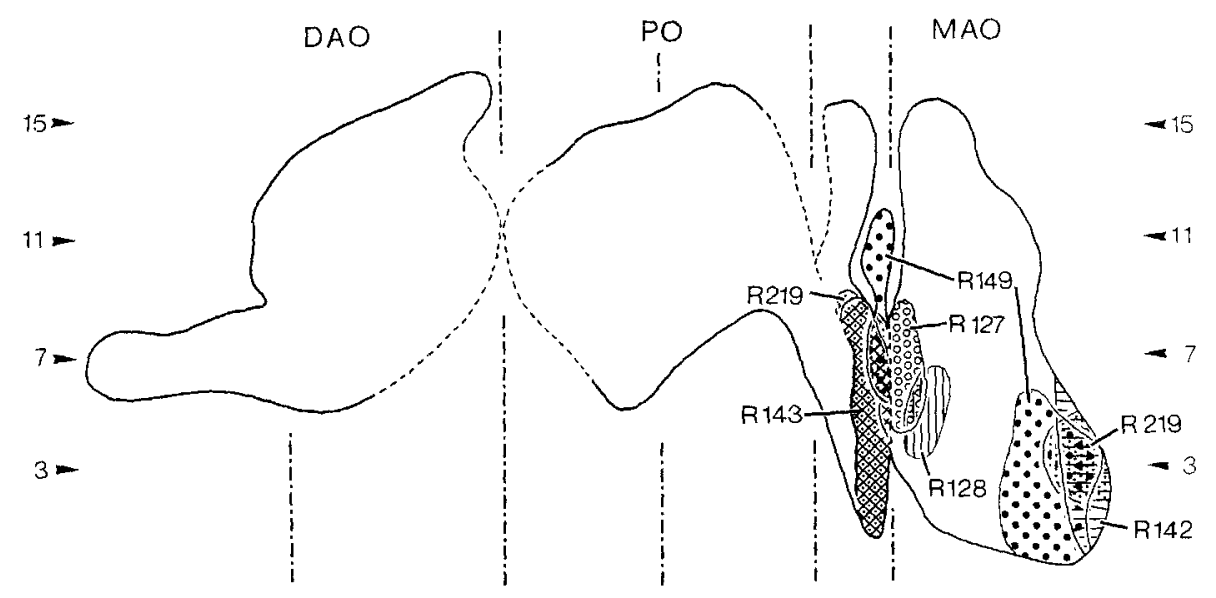

Figure 3 
R177, anterograde labelling in the VLPO extended into its bend (Fig. 7). Note that due to the incorporation of a small part of the caudolateral PIN in the injection site, a small sliver of the medial part of the rostral MAO also showed terminal labelling. The caudal bend and the adjacent dorsal leaf of the principal olive (DLPO) were labelled in case R96 (Fig. 7B), with an injection located in the most rostroventral part of the LCN. The injection site in case R132 occupied the rostral two-thirds of the central LCN. It overlapped with R131 but is located more ventrally. The resulting labelling was confined to the DLPO, partially overlapping with $\mathrm{R} 96$, but absent from the region of the bend. The injection in case $\mathrm{R} 131$ also resulted in labelling of the DLPO at intermediate levels along the rostrocaudal axis. However, labelled terminal arborizations were also encountered within the VLPO (Fig. 7). Here, contrary to cases R96 and R177, no continuity between both labelled areas could be observed along the lateral bend of the PO. This pattern of olivary labelling was caused by an injection that may be characterized as intermediate along the rostrocaudal axis of the LCN. It is situated dorsolaterally, although central areas of the LCN also may have picked up the tracer.

An interesting injection was presented by case R182 (Figs. 6F, 7A). Here, the injection was centered rather caudally into the ventromedial part of the parvicellular LCN, ventrally touching upon the " $y$ " nucleus and extending rostrally into the AIN. The resulting olivary labelling was found in the VLO (Figs. 6G, 7B,C). Labelling in the rostral part of the DAO is caused by the AIN participation in the injection site (see below). A group "Y" origin of the VLO labelling seems unlikely since an injection centered within this nucleus and resulting in dense terminal labelling within oculomotor areas (case R172, not shown), failed to give any labelling within the inferior olivary complex.

When analysing these cases, it is obvious that caudal, medial and ventral areas of the LCN tend to project to the VLPO, whereas rostral, lateral, and dorsal areas are connected with the DLPO. The bend of the PO is likely to be innervated from the ventrolateralmost areas of the LCN. Furthermore, a clear tendency was observed for rostral LCN areas to project to caudal levels of the PO, whereas caudal LCN areas project to rostral levels (compare, e.g., cases R96, R131, and R133, respectively). Finally, the VLO receives afferents from a small area localized in the ventromedial part of the LCN.

\section{Injections centered on the dorsolateral hump (DLH)}

Korneliussen ('68) defined the DLH as an area that comprises the lateral fourth of the AIN including a rostrally positioned dorsolateral protrusion consisting of rather small cells (Voogd et al., '85) and a caudally positioned dorsolateral protrusion consisting of larger cells and that lies intercalated between the PIN and LCN. Some authors, however, define the DLH as part of the LCN (e.g., Angaut and Cicirata, '82). For this reason and since the efferent connections of this part of the cerebellar nuclei seems to be unique for certain rodents (Cajal, '03, '11; Mehler, '67, '69; Woodson and Angaut, ' 84 ), we describe the olivary projections from the DLH in a separate section.

Two injection sites fell almost completely within the confines of the DLH. The injection site in case R138 (Figs. $8 \mathrm{~A}, 9 \mathrm{~A}$ ) was centered on the rostrally positioned protrusion, whereas the injection site in case $R 139$ was focussed on its caudal pole (Fig. 8A). In both cases, labelled fibers left the cerebellum through the ipsilateral scp, taking up intermediate positions in the bundle. Many fibers left the ventromedial aspect of the scp before its decussation, to descend ipsilaterally.

In the contralateral olive, high density afferent labelling was observed specifically within the dorsomedial group (DM). Case R138 demonstrated labelling within the rostralmost two-thirds of the DM, whereas case R139 labelled the caudal half of this cell group (Fig. 8B,C). Moderately dense labelling was also observed in the DM of the ipsilateral side (Fig. 9B). Injections, directly ventral to the DLH (as in case R24, Fig. 8, but also, e.g., in case R98, see below and Fig. 10) did not result in labelling of the DM group, but showed labelling within the DAO.

Concluding, we propose that the caudal and rostral pole of the DLH constitute a continuum of cells that projects to this dorsomedial group of cells of the rat inferior olive.

\section{Injections centered on the anterior interposed nucleus (AIN)}

The injection sites in four cases (R89, R98, Fig. 10A; R90, Fig. 9C; R38, not shown) fell almost completely within the confines of the AIN. Five additional cases were considered with injections extending in other nuclei (R99, R26, Fig. 10A; R182, Fig. 7A; R24, Fig. 8A, and R18, not shown).

All labelled fibers left the cerebellum through the intermediate and dorsolateral segments of the ipsilateral scp. As was noted with injections centered on the DLH, injections involving the lateral AIN (R38, R90, R98, R24), all included a major ipsilaterally descending pathway. However, also in these cases, it was the contralaterally descending pathway that contained the olivary directed fibers.

All injections involving the AIN resulted in high density terminal labelling within the DAO. The lateral injection sites in cases R98 (Fig. 10), R38 and R90 (Fig. 9C,D), resulted in labelling of the rostromedial DAO. The injection site in case R89 (Fig. 10A) was positioned medially in the rostral AIN. Here, the nucleo-olivary fibers terminated within the lateral part of the DAO, with the exception of its dorsal fold (Fig. 10B,C). Caudomedial AIN, including the dorsomedial crest, was injected in case R99 (Fig. 11A). Although in this case the injection site also involved parts of the MCN and PIN, it was demonstrated in other experiments that these areas do not project to the DAO. Therefore, the labelling in the caudal DAO can be attributed to the specific part of the AIN involved. In case R26, the injection extended ventrally into the lateral vestibular nucleus (LVN). Moderately dense labelling now involved
Fig. 3. Diagrammatic representations of experiments with injections in the MCN. A. PHA-L injection sites of six cases are shown, redrawn in a double row of the diagrammatic representation of the nuclei as shown in Figure 1. Cases R128, R142, and R143 are shown in the left-hand rows; cases R127, R149, and R219 are shown in the right-hand rows. B. Patterns of PHA-L labelled terminal arborizations of these six cases, redrawn in the diagrammatic representation of the inferior olive as shown in Figure 2A. C. Schematic representation of the labelling in the unfolded olive. Note that the DC has been omitted in order to reveal the total rostrocaudal extent of group "beta." Symbols in $\mathrm{C}$ correspond to those used in $\mathrm{A}$. 

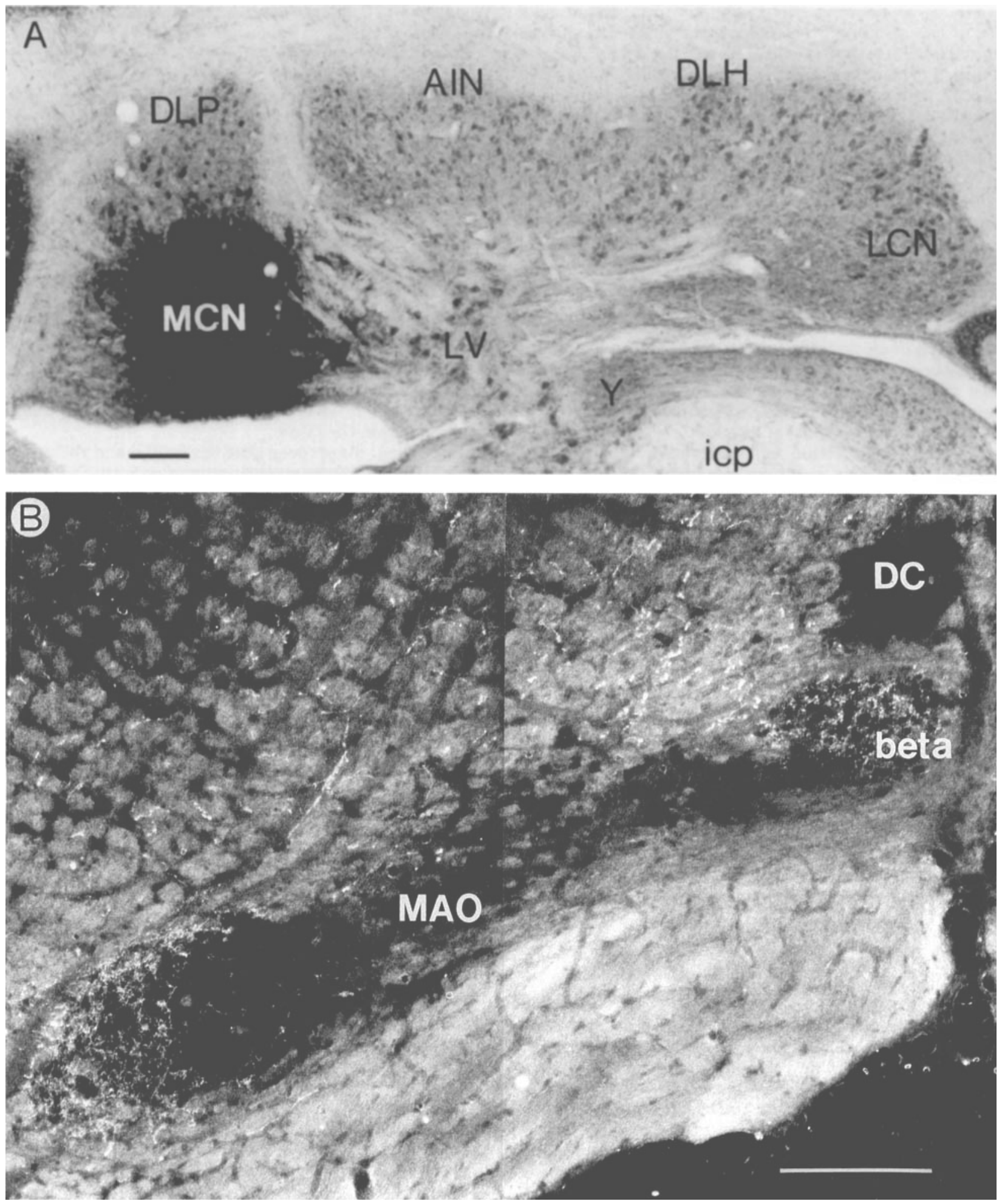

Fig. 4. Light- and darkfield photomicrographs of case R219. A. PHA-L injection site in the MCN, approximately level 7 of Figure 1. B. Anterograde labelling within the lateral part of the caudal MAO and within the "beta" group (appr. level 3 of Fig. 2A). Note labelling of fibers dorsal to the olive. Bars equal 200 $\mu \mathrm{m}$ 
the caudally positioned dorsal fold of the DAO (Fig. 10). The latter projection can be attributed to the LVN, since an injection centered within this nucleus resulted in a definite labelling restricted to the dorsal fold of the DAO and to the lateral part of the caudal MAO (case R157, Fig. 9E,F, Fig. 10). It is noteworthy that besides labelling of fibers in the lateral (uncrossed) and medial (crossed) vestibulospinal tracts, this LVN injection also resulted in labelling of fibers ascending within the ipsilateral scp, crossing within the mesencephalon and descending in the contralateral brainstem in positions comparable to the cerebello-olivary fibers. Other cases with injections of the AIN extending in the LCN and/or PIN (R18, not shown; R182, Fig. 7; R24, Fig. 8) are compatible with the general notion of a mediolateral representation in the DAO of a caudolateral to rostromedial axis in the AIN. The dorsal fold is not innervated from any of the cerebellar nuclei but receives afferents from the LVN.

\section{Ipsilateral olivary projections}

In most cases, labelling of fine terminal arborizations could also be observed within the inferior olive ipsilateral to the injection site. This ipsilateral labelling was invariably found within the same areas as the ones containing terminal labelling on the contralateral side. Labelled fibers could be observed to cross the midline between, or just rostral to, both areas of terminal labelling (e.g., in case R138 see Fig. 9B). Since no labelled fibers were found descending ipsilaterally at similar positions as the crossed nucleo-olivary fibers, we assume that the descending nucleo-olivary pathway is completely crossed and that the ipsilateral olivary labelling consists of fibers recrossing the midline just rostral to, and at the level of, the inferior olive.

The amount and density of this recrossed olivary labelling varied for different regions of the cerebellar nuclei. The most abundant ipsilateral labelling resulted from injections in the DLH (i.e., in the DM, Fig. 9B) and in the PIN (i.e., in the rostral MAO, Fig. 6D). A fair amount of ipsilateral labelling was usually observed in the VLPO after an injection in ventromedial areas of the LCN. Ipsilateral labelling was sparse or absent within the DAO and its dorsal fold, DLPO, group "beta," and in the caudal MAO (i.e., after injections in the AIN, LVN, dorsolateral LCN, and MCN, respectively).

\section{DISCUSSION}

The anterograde tracer Phaseolus vulgaris leucoagglutinin (PHA-L) was used to study the nucleo-olivary projection in the rat. Small iontophoretic injections, in many instances covering only a part of the individual cerebellar nuclei, resulted in anterograde labelling of preterminal and terminal fibers within circumscript areas of the inferior olive. PHA-L has distinct advantages over wheat germ agglutinate coupled horseradish peroxidase (WGA-HRP), which was often used as a tracer of the nucleo-olivary projection (Dietrichs and Walberg, '85, '86; Dietrichs et al., '85; Billard et al., '89; Ikeda et al., '89), because retrogradely labelled olivary neurons and their dendrites and axons do not hamper the analysis. The small size of the injection sites, the possibility to distinguish varicosities and intervaricose segments, and the absence of delay in the immunohistochemical detection of PHA-L, all compare favourably with the autoradiographic localization of triticiated amino acids as anterograde tracers, especially in small rodents.

\section{Nucleo-olivary pathways}

Nucleo-olivary fibers from all cerebellar nuclei take up positions in the scp. The topography of the fiber contingent from different nuclei within the scp was very similar to the one described by Haroian et al. ('81). After crossing within the decussation of the scp, labelled, small caliber fibers could be observed to take a descending route (Faull, '78). Just caudal to the pontine nuclei only very thin (diam. < $1.5 \mu \mathrm{m}$ ) fibers continued their descending route as a loosely packed bundle, dorsal and lateral to the pyramidal tract and medial lemniscus, from where they entered the inferior olive. The olivary directed fibers from the lateral vestibular nucleus (LVN) take a similar course. Ipsilateral olivary projections result from recrossing of fibers at, or just rostral to the inferior olive (Chan-Palay,'77).

Injections into the MCN resulted in labelled fibers that left the cerebellum via different routes (Voogd et al., '85). Abundant terminal labelling in the contralateral paramedian reticular formation obscured the pathway through which the fibers from the MCN reached the olive.

\section{Density of the nucleo-olivary projections}

In the cat, but also in the rat, it has recently been demonstrated that most, if not all, of the nucleo-olivary terminals are GABA-ergic (Nelson et al., '84; Angaut and Sotelo, '87, '89; De Zeeuw et al., '88, '89a,b, '90) and account for the bulk of the GABA-ergic input to the inferior olive (Nelson et al., '84; Nelson and Mugnaini, '85, '89; De Zeeuw et al., '88, '89a,b). Sotelo et al. ('86) using an antibody directed against the GABA-synthetizing enzyme, glutamic acid decarboxylase: GAD, demonstrated in the rat that the density of GAD-positive terminals is largely homogeneous throughout the olive, although clear differences exist with respect to the size and staining intensity of the labelled terminals (see also Nelson and Mugnaini, '88). However, we observed that the density of PHA-L labelled terminals within the caudal MAO, group "beta," VLO and DMCC, and dorsal fold of the DAO was always lower compared to the heavy, massed projections observed within the rostral MAO, PO, DAO, and DM. This suggests that in the former group most of the GAD-labelled terminals are derived from one or more extracerebellar sources, as was also suggested by Sotelo et al. ('86) and for which Nelson and Mugnaini ('89) recently presented evidence. The relative paucity of cerebellar nuclear afferents within the caudal MAO and group "beta" is in good accordance with the scarcity of GAD-positive neurons within the MCN (Mugnaini and Oertel, '81, '85; see also Buisseret-Delmas et al., '89), which, as discussed below, is the main cerebellar source of afferents for these olivary regions.

Ipsilateral nucleo-olivary projections were already noted earlier in various species (rat: Brown et al., '77; ChanPalay, '77; Angaut and Cicirata, '82; Swenson and Castro, '83a,b; cat: Beitz, '76; monkey: Chan-Palay, '77; Kalil, '79). Usually, the ipsilateral labelling was distributed as the mirror image of the contralaterally labelled areas. Large differences, however, were found with respect to the density of the recrossed nucleo-olivary projection. Especially in the DM, the rostral MAO, and the VLPO extensive, ipsilateral projections were observed; projections that were formerly described as minor (Angaut and Cicirata, '82; Swenson and Castro, '83a) or nonexisting (rostral MAO: Angaut and Cicirata, '82). 

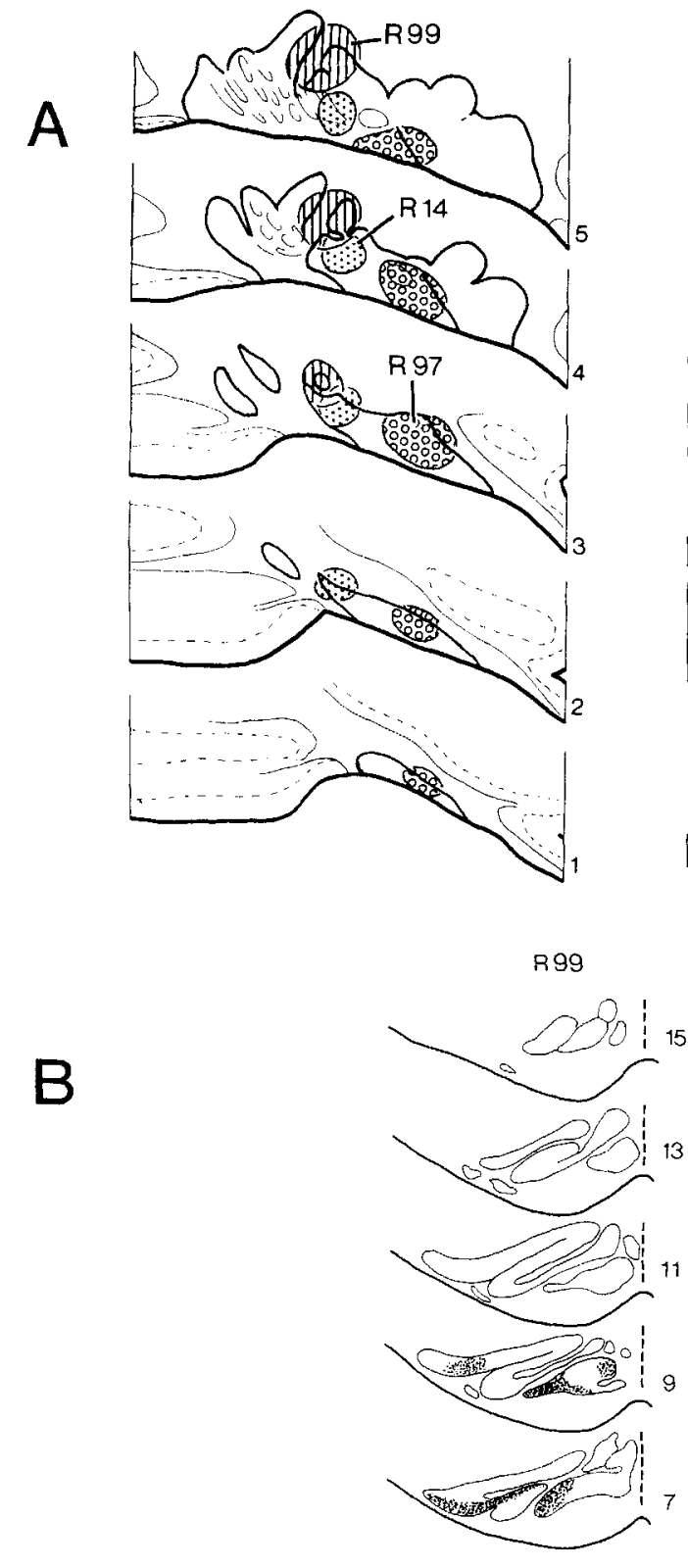
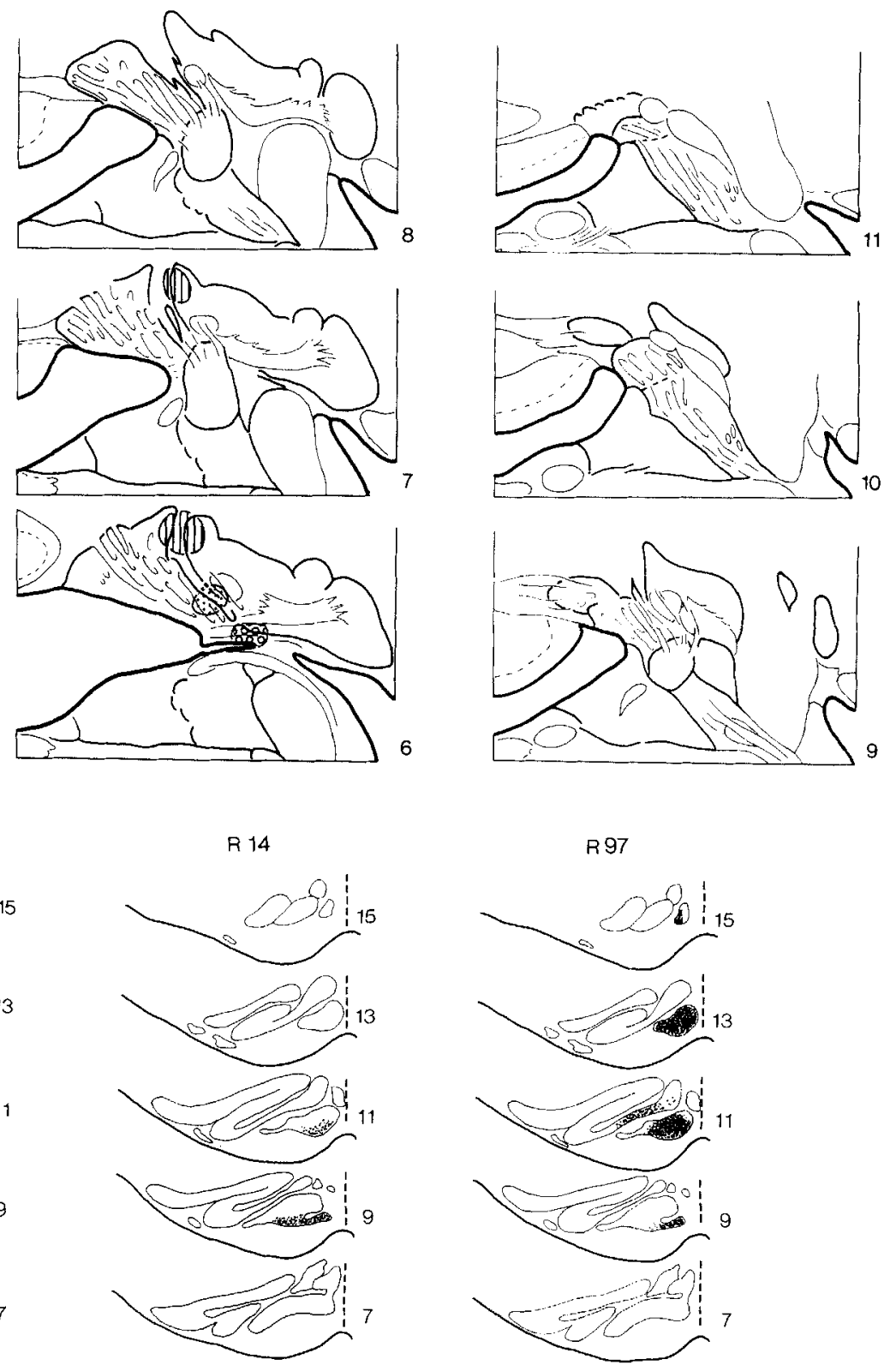

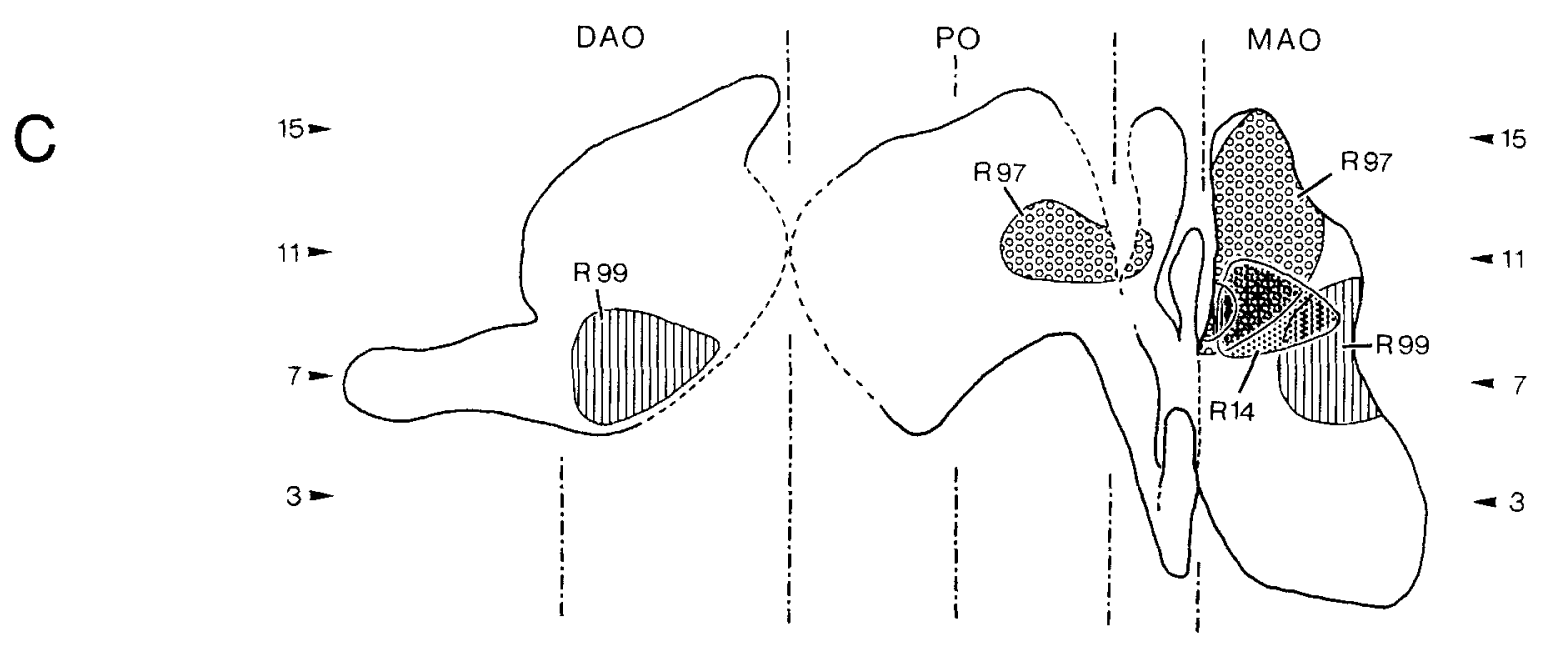

Figure 5 


\section{Projections of the medial cerebellar nucleus (MCN) to the caudal medial accessory olive (MAO)}

Projections from the MCN to the inferior olive have been disputed. In the rat, negative findings have been reported by Brown et al. ('77) using retrograde transport of HRP, whereas, with anterograde $3 \mathrm{H}$-leucine tracing, both negative (Haroian, '82) as well as positive results (Angaut and Cicirata, '82; Swenson and Castro, '83a) were obtained. Contradictory findings were also reported for other mammals. In the cat, negative findings were published by Buisseret-Delmas and Batini ('78), Graybiel et al. ('73), Tolbert et al. ('76), and Courville et al. ('83), whereas positive findings were reported by Dietrichs and Walberg ('85) and Sugimoto et al. (' 80 ). In the monkey, negative results were obtained in anterograde tracer studies of projections from the fastigial nucleus (Batton et al., '77; Kalil, '79; Asanuma et al., '83). Recently, Ikeda et al. ('89) reported projections from the central and caudal parts of the fastigial nucleus to the caudal MAO, using anterograde transport of WGA-HRP in the macaque monkey.

Our experiments give clear evidence for a projection from the MCN to the caudal regions of the MAO in the rat. Injections centered on different areas revealed that: (1) rostral regions of the MCN project to the lateral parts of the caudal MAO, (2) the DLP projects to the medial part of the caudal MAO, (3) the "beta" group is provided by cerebellar afferents from more caudal and lateral regions of the MCN, and (4) the ventrolateral-most part of the MCN gives rise to a projection to the DMCC.

Projections from the caudal part of the MCN to the caudal part of the MAO including group "beta" but also the VLO were described by Angaut and Cicirata ('82) and Swenson and Castro ('83a). In our material we were unable to note a VLO projection resulting from injection of the MCN, although in some cases labelling was found in the rostral part of the "beta" group, positioned directly medial to the VLO (Fig. 2, see also Fig. 3, cases R219 and R143 at appr. level 8). Recently, Buisseret-Delmas et al. ('89) located the GABA-ergic nucleo-olivary neurons in the ventral part of the MCN. However, in our material, all injections in the MCN, including those in the DLP, resulted in terminal labelling within the olive.

The organization of the rat fastigio-olivary projection seems to be different with respect to the situation in the cat (Dietrichs and Walberg, '85). They noted that the middle part of the fastigial nucleus projects to group "beta" and the DC; lateral parts of the nucleus were found to project to the lateral parts, whereas medial parts of the fastigial nucleus mainly project to the medial parts of the caudal MAO. No mention was made of a projection to the DMCC from the ventrolateral MCN in cat, whereas in rat, we were unable to detect a projection from the MCN to the DC.

Fig. 5. Diagrammatic representations of three experiments with injections in the PIN. A. PHA-L injection sites. B. Patterns of terminal arborizations in the inferior olive. C. Schematic representation of the labelling in the unfolded olive. Symbols in C correspond to those used in A.

\section{Projections of the posterior interposed nucleus (PIN) to the rostral medial accessory olive (MAO)}

A projection from the PIN to the rostral part of the MAO has been described by all authors investigating the subject (e.g., oppossum: Martin et al., '76; rat: Achenbach and Goodman, '68; cat: Tolbert et al., '76; monkey: Kalil, '79). However, opinions differ on the precise topographical relation between both nuclei. In the cat, Tolbert et al. ('76) found a projection of the rostral parts of the PIN to rostral parts of the rostral MAO, Courville et al. ('83) traced this rostral projection to medial parts of the rostral MAO, whereas in the monkey, Kalil ('79) indicated a rostrocaudal inversion in the projection. In our material, we noted a gradient in the PIN from caudolateral to rostromedial corresponding with projections to the rostral pole and to more caudolateral parts of the rostral MAO, respectively.

\section{Projections of the lateral cerebellar nucleus (LCN) to the principal olive (PO)}

Most detailed information is available on the topographical relations between the LCN (dentate nucleus) and the PO. In humans (Lapresle and Ben Hamida, '70), and monkeys (Chan-Palay, '77; Kalil, '79), these connections are organized in such a way that the dorsal and ventral dentate projects to the dorsal and ventral leaf of the PO, respectively. Within the lamellae the rostrocaudal component is reversed. According to Chan-Palay ('77), the medial, hilar portion is represented in the medial tip of the VLPO, the lateral periphery in the medial tip of the DLPO. The other authors state that the mediolateral topology is maintained in the projections to both lamellae.

In the cat, the mediolateral and dorsolateral topology is maintained according to a report by Tolbert et al. ('76), whereas the rostrocaudal topology was found to be essentially noninversed (Beitz, '76). Dietrichs et al. ('85) related transverse levels in the dentate nucleus to rostrocaudal levels in the PO (dorsal LCN projecting to both lamellae of the rostral $\mathrm{PO}$, ventrolateral $\mathrm{LCN}$ to the intermediate $\mathrm{PO}$, whereas the ventromedial LCN projects to the VLO).

Also in the rat, the LCN has been shown to project to the PO (Angaut and Cicirata, '82; Haroian, '82; Brown et al., '77; Swenson and Castro, '83a,b). Swenson and Castro (' $83 \mathrm{~b}$ ) described a rostral and a caudal component within the LCN, related to DLPO and VLPO, respectively. Our results are in general agreement with Angaut and Cicirata ('82) who suggest the maintenance of the transverse topology in the projection of the LCN to the PO. Besides a mere transverse relationship, also an inversed rostrocaudal topology could be recognized. Since the LCN and PO both consist of a folded sheet of cells, we conject that he caudomedial and dorsolateral "leaf" of the LCN innervate the VLPO and DLPO, respectively, whereas the lateral bend of the PO receives a projection from the ventrolateral $L C N$. The projection from the most ventromedial part of the LCN to the VLO is in accordance with this concept. The reciprocal projection from the VLO to a small part of the medioventral (parvicellular) LCN has recently been demonstrated in the rat (Ruigrok and Voogd, '88b; Van der Want et al., '89).

\section{Projection of the dorsolateral hump (DLH) to the dorsomedial group (DM)}

The DLH was defined as a group of small cells forming a dorsal protrusion between the AIN and the LCN (Goodman 

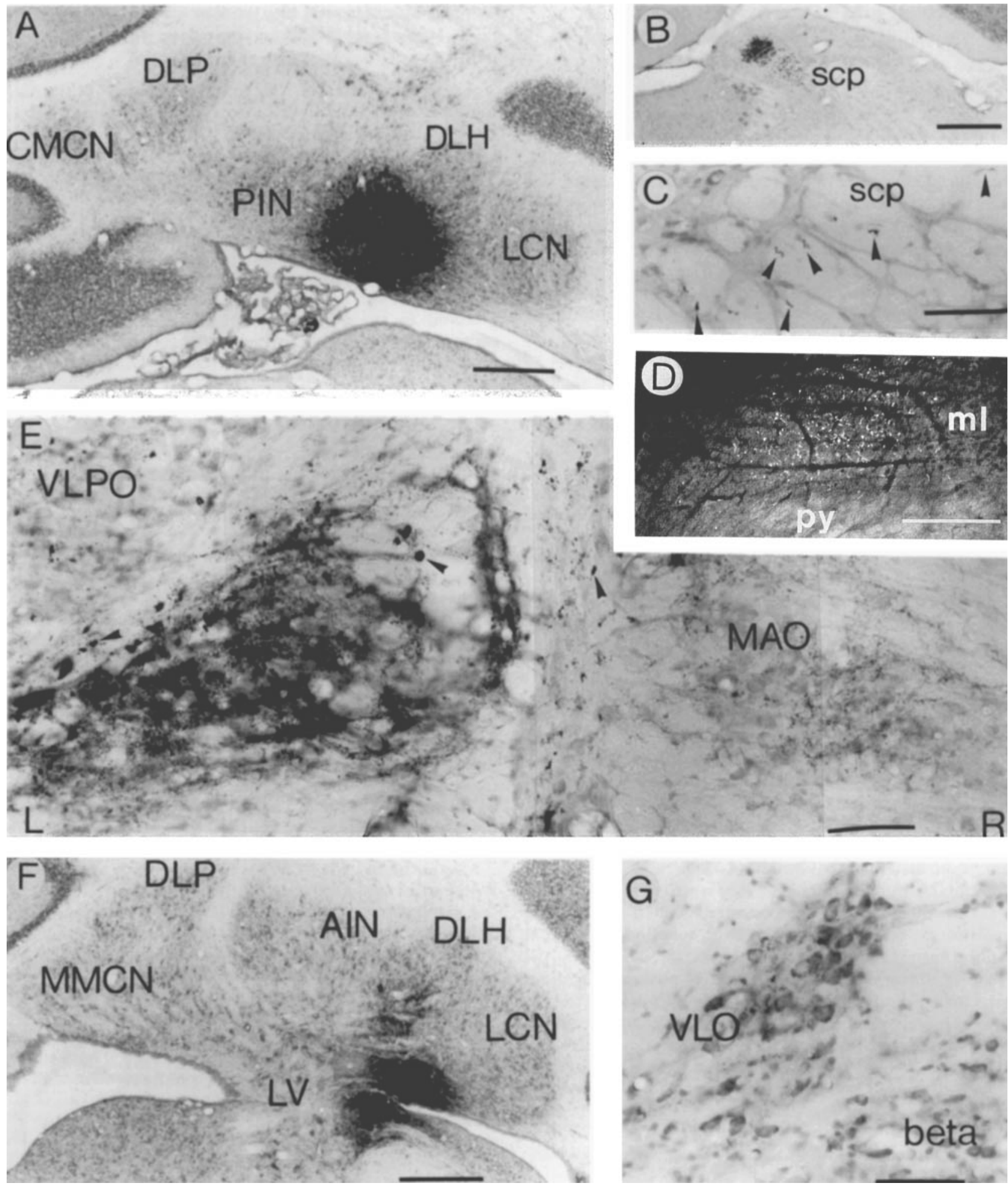

Fig. 6. Light- and darkfield photomicrographs of cases R97 (A, $B, C, D, E)$ and $R 182(F, G)$. A. PHA-L injection site in lateral part of PIN (appr. level 4 of Fig. 1). B. PHA-L labelled fibers within the medial part of the ipsilateral scp (labelled ${ }^{*}$ in Fig. 1). C. Some labelled fibers (arrowheads) are also seen in the contralateral scp, their positions are not related to those on the ipsilateral side. D. Darkfield photomicrograph of a transverse level caudal to the basal pontine nuclei and rostral to the olive. Thin PHA-L labelled fibers, destined for the inferior olive are found dorsal to the pyramidal tract contralateral to the injection site. E. Anterograde terminal labelling within the rostral MAO of the contralateral, but also of the ipsilateral side (appr. level 13 of Fig. 2A). Heavy black dots (arrowheads) are deposits of gold-labelled WGA-BSA complex, which was injected into the olive in some experiments (see Materials and Methods). F. PHA-L injection site in the ventromedial part of the LCN, involving AIN and nucleus y (appr. level 7 of Fig. 1), G. Sparse labelling of terminal arborizations in the VLO. Bars equal 500 $\mu \mathrm{m}$ in $\mathrm{A}, \mathrm{B}, \mathrm{F}$, and $100 \mu \mathrm{m}$ in $\mathrm{C}, \mathrm{D}, \mathrm{E}, \mathrm{G}$. 

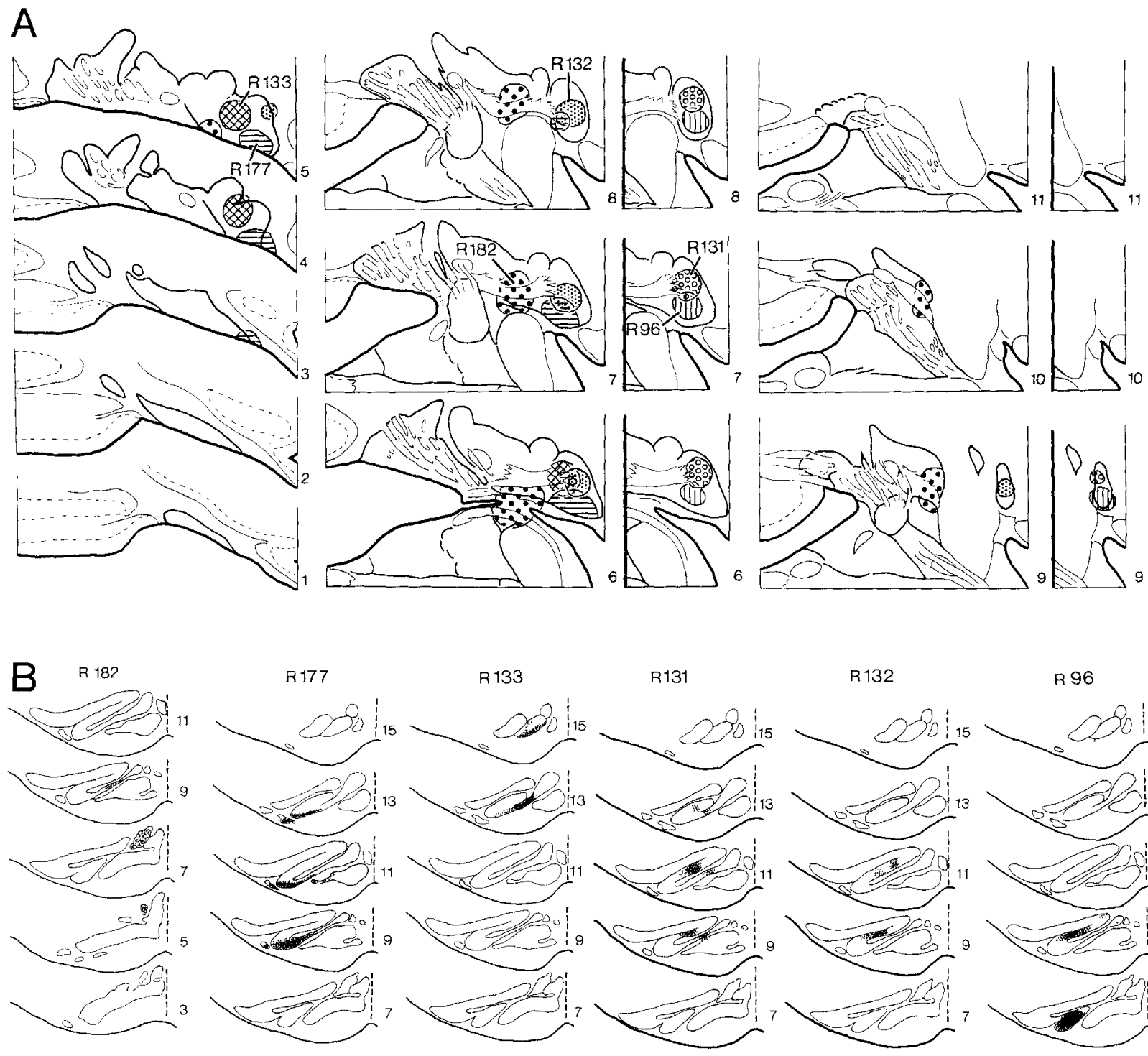

R133

R131

$\mathrm{R} 132$

R 96
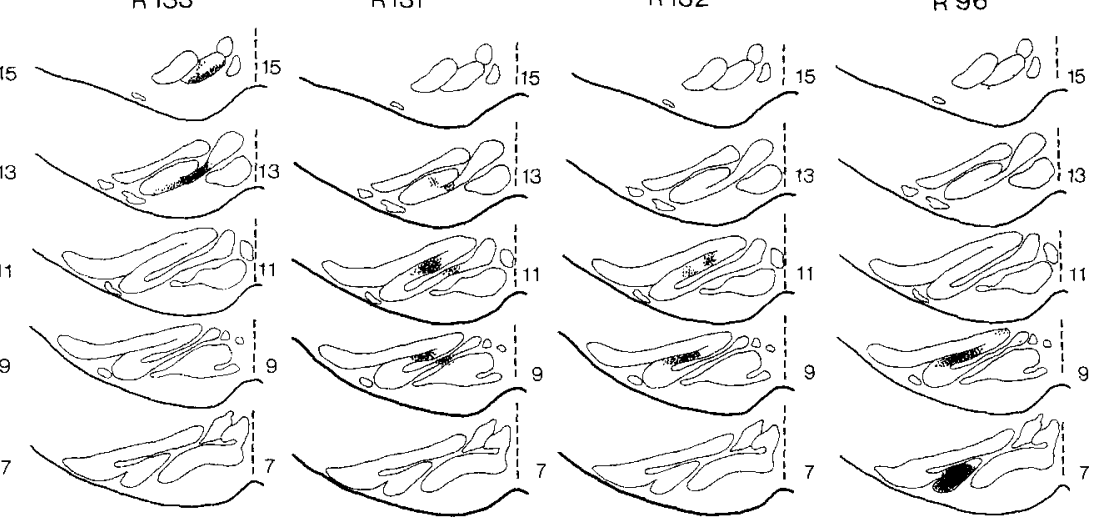

C

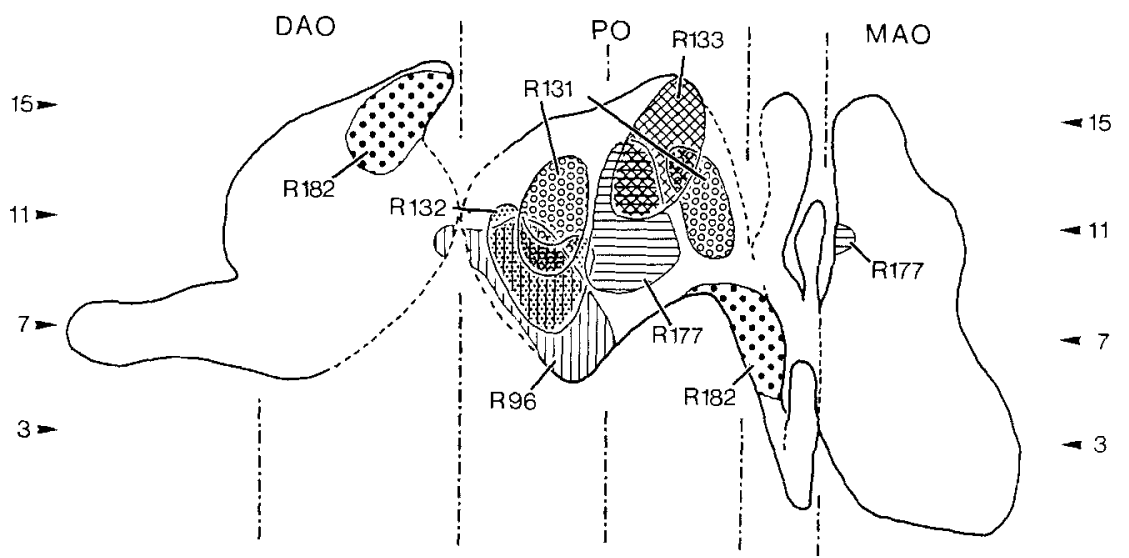

Fig. 7. Diagrammatic representation of six experiments with injections in the LCN. A. Left-hand rows (of levels 6 to 11) show injection sites of cases R132, R133, R177, and R182). Right-hand rows (of levels 6

to 11) show injection sites of cases R96 and R131. B, C: As Figure 5. Note that the labelling in the rostral DAO (case R182) is not shown in B. 


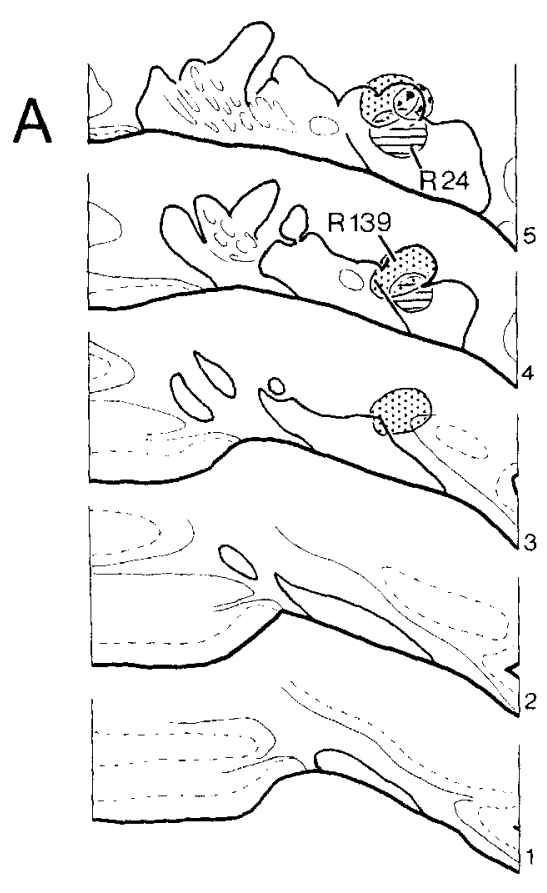

R 24

B

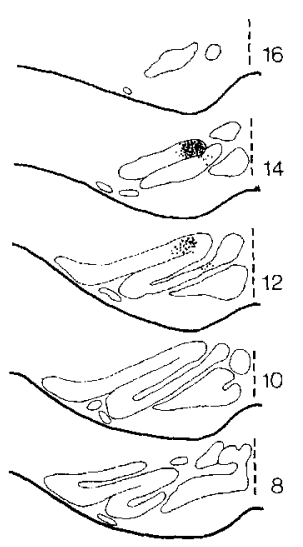

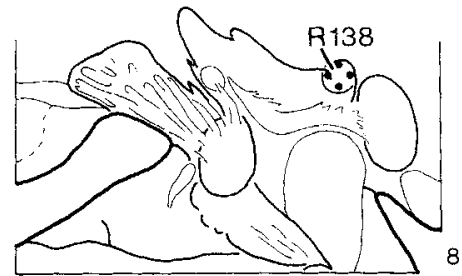
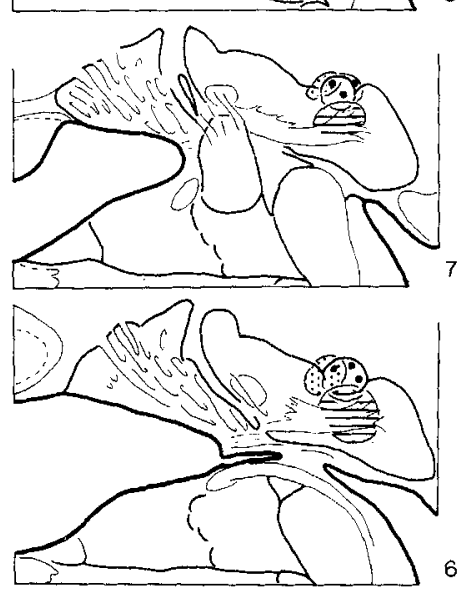

R 138

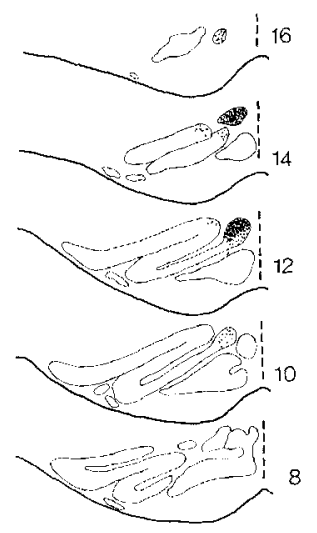

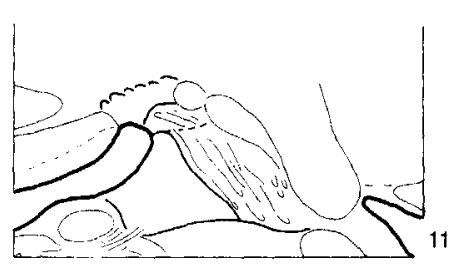
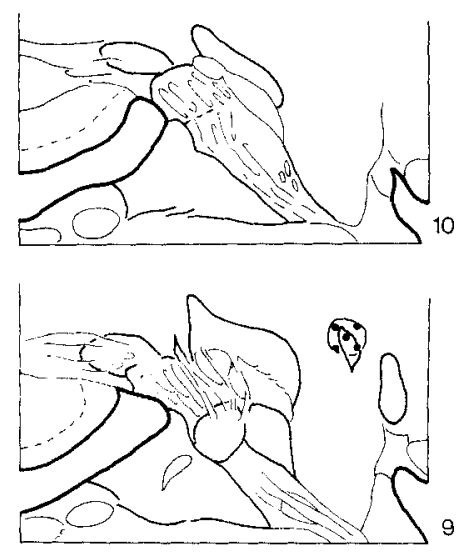

$R 139$

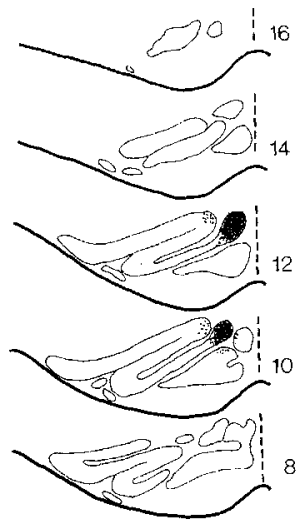

C

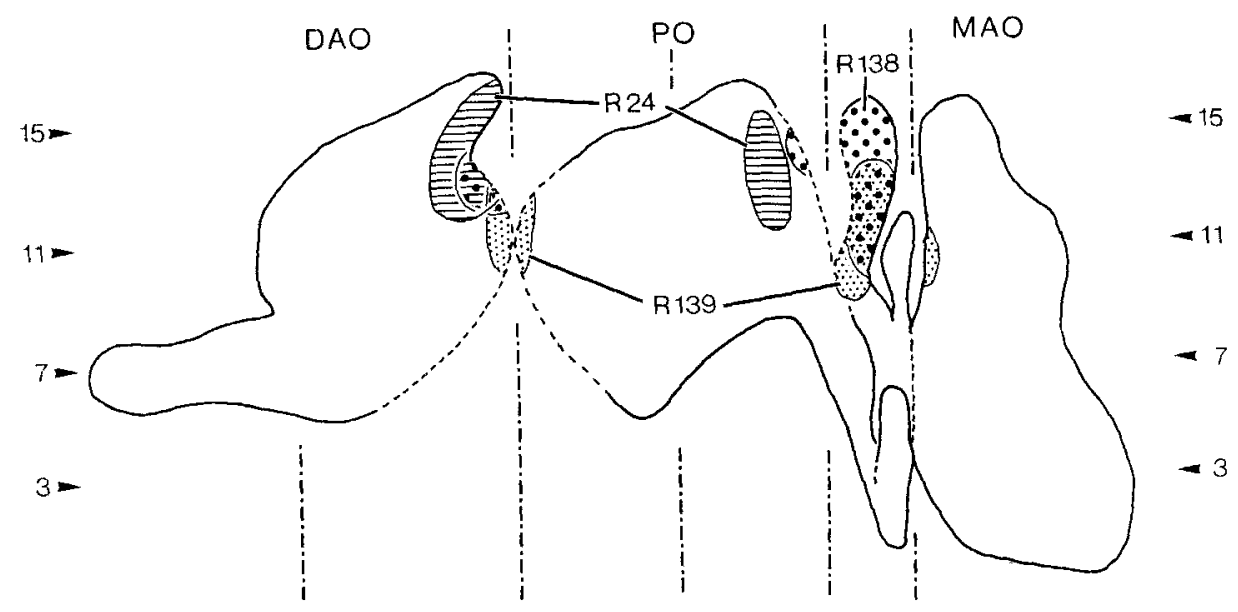

Fig. 8. A,B,C. Diagrammatic representation of two experiments (R138 and R139) with injections in the $\mathrm{DLH}$ and one (R24) with an injection just ventral to the DLH, further as Figure 5. 

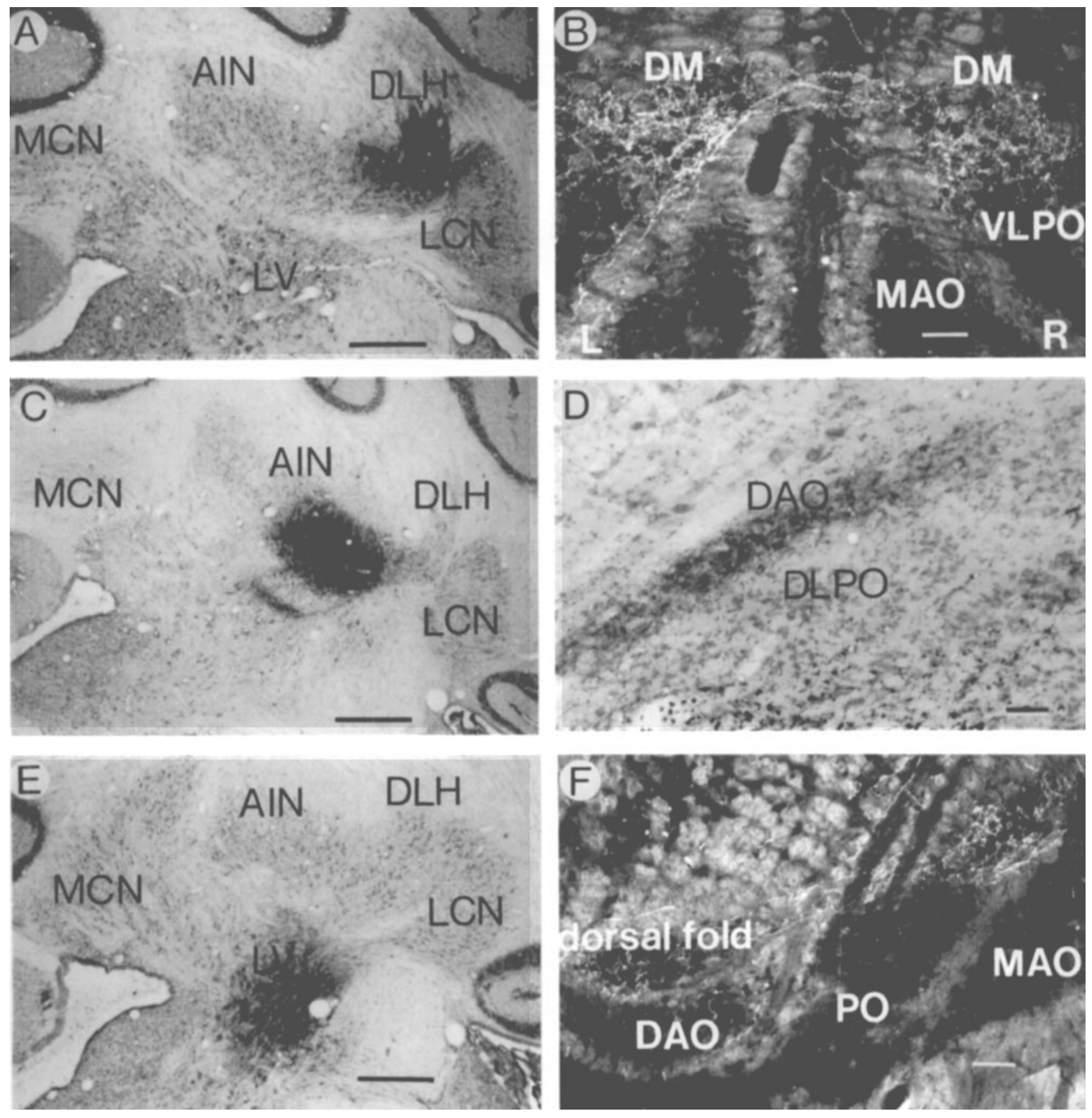

Fig. 9. Light- and darkfield photomicrographs of cases R138 (A,B), R90 (C,D) and R157 (E,F). A. PHA-L injection site in the rostral part of the DLH (appr. level 8 of Fig. 1). B. Resulting anterograde labelling in the contra- and ipsilateral DM group of the inferior olive (appr. level 13 of Fig. 2A). C. PHA-L injection site in the lateral part of the AIN (appr. level 9 of Fig. 1). D. Resulting anterograde labelling within the DAO

et al., '63; Korneliussen, '68). This cell group gives rise to the uncrossed, descending limb of the scp (Cajal, '11; Mehler, '67, '69; Chan-Palay, '77; Faull, '78; Woodson and Angaut, '84). In our material, the origin and termination of this ipsilaterally descending pathway was confirmed. However, injections in the AIN ventral and medial to the rostral DLH and in the caudal DLH (between PIN and LCN) also labelled the uncrossed descending limb of the scp.

(appr. level 12 of Fig. 2A). Note the black deposits of the gold-labelled WGA-BSA complex (see also Fig. 6E). E. PHA-L injection site in the LVN (appr. level 7 of Fig. 1). F. Anterograde labelling within the dorsal fold of the DAO (appr. level 9 of Fig. 2A). Bars equal $500 \mu \mathrm{m}$ in A, C, E, and $100 \mu \mathrm{m}$ in $\mathrm{B}, \mathrm{D}, \mathrm{F}$.

The pattern in the nucleo-olivary projection of the DLH is consistent with its characteristic position. The DLH gives rise to heavy anterograde labelling in the dorsomedial group (DM). The rostrocaudal topology in DLH is maintained in this projection. Cell groups in the lateral AIN that also contribute to the ipsilaterally descending pathway are distinguished by their connections with the contralateral DAO. 


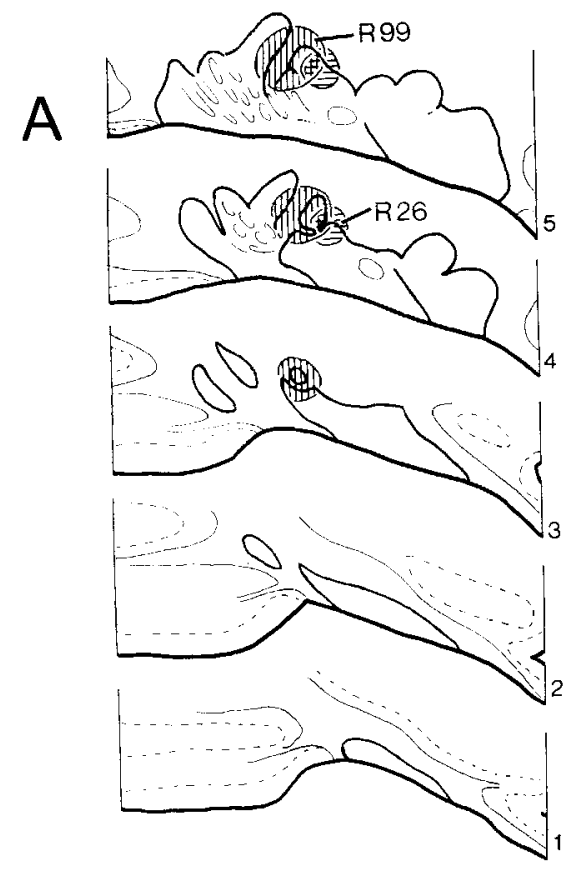

$\begin{array}{ll}\text { R } 98 & \text { R } 89\end{array}$
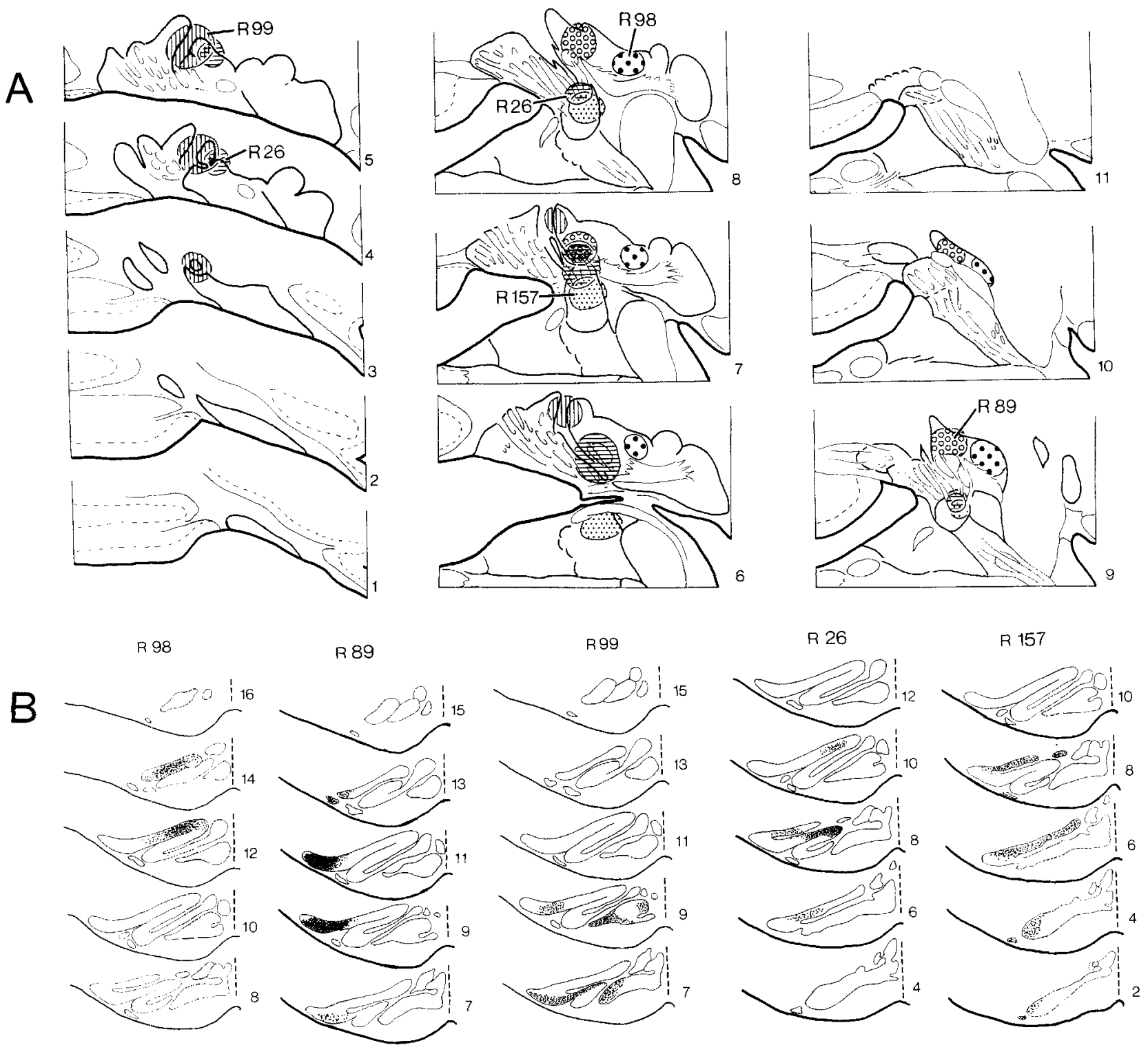

C

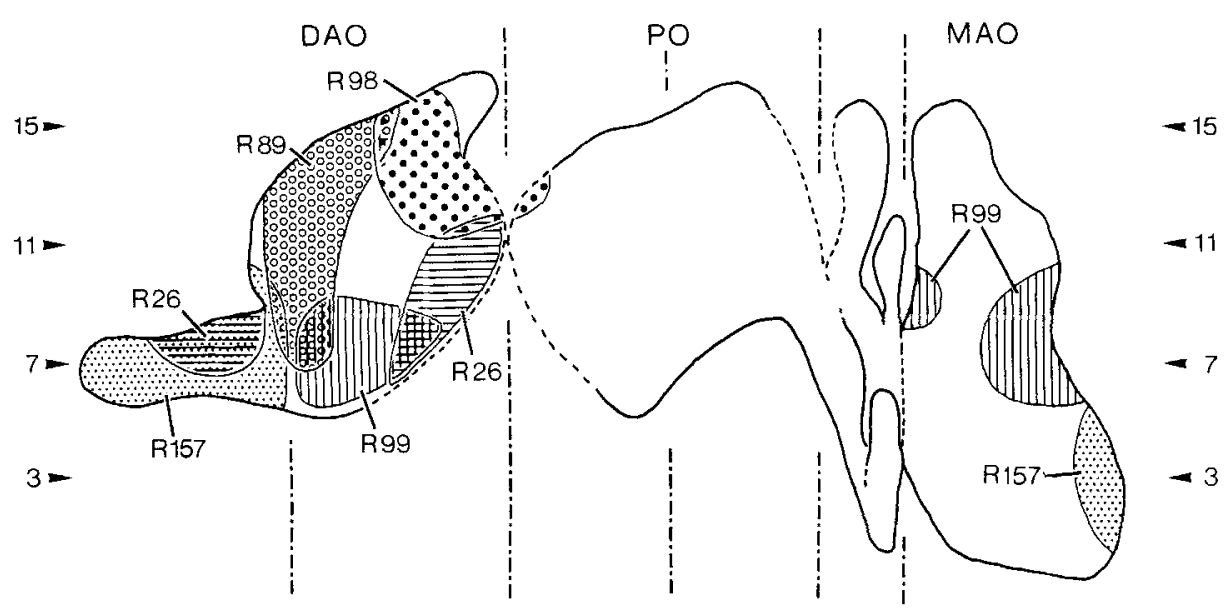

Fig. 10. A,B,C. Diagrammatic representations of five experiments with injections in the AIN and LVN, further as Figure 5. Note that case R99 was also shown in Figure 5. 


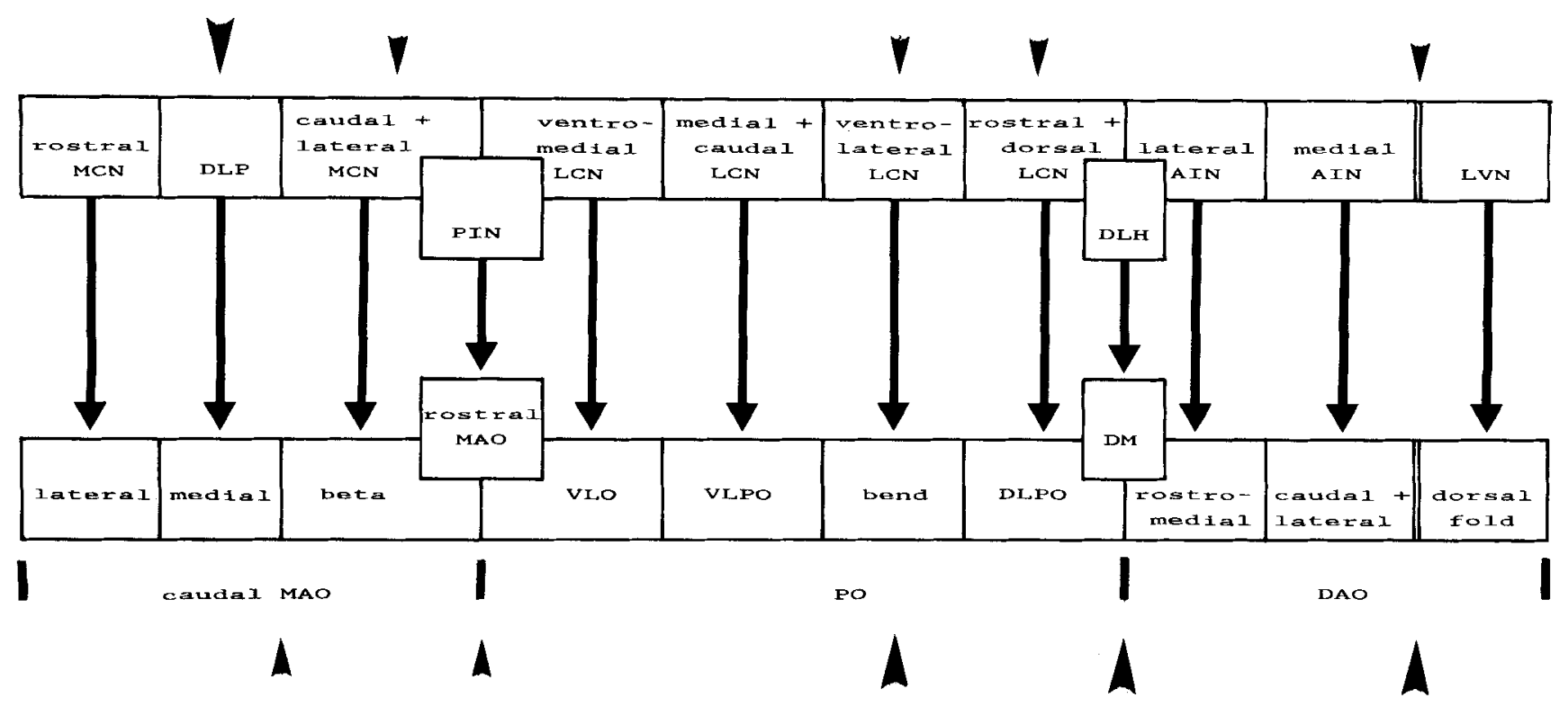

Fig. 11. Schematized cerebellar nucleo-olivary relationships. The cerebellar nuclei and olivary nuclear complex and visualised as unfolded continuous sheets of cells. Basic folding places of both sheets are indicated by large (appr., $180^{\circ}$ ) and small (appr. $90^{\circ}$ ) arrowheads. See text for further explanation.

Some authors refer to the DM group as the dorsomedial cell column (DMCC: Angaut and Cicirata, '82; Huerta et al., '83; Swenson and Castro, '83a,b; Sotelo et al., '86). However, since the DMCC is part of the MAO and forms a rostral continuation of group "beta" in most species (Whitworth and Haines, '86), we subscribe to the view (Gwyn et al., '77; Azizi and Woodward, '87; Bernard, '87; Nelson and Mugnaini, '88) that the DMCC is positioned directly dorsomedial to the MAO, terminating rather abruptly just rostral to the point where it appears to merge with the contralateral DMCC. In contrast, the DM appears as a rostral continuation of the VLO and can be distinguished as a conspicuous bulge dorsomedial to the VLPO and directly medial to the DLPO-DAO transition. This position of DM and DLH may be unique for the rat and possibly also for other members of the Rodent order (Mehler, '67). Therefore, the DLH deserves its distinct position in rat cerebellar nuclear terminology and should not be incorporated in either LCN or AIN.

\section{The projections of the anterior interposed nucleus (AIN) and the lateral vestibular nucleus (LVN) to the dorsal accessory olive (DAO)}

The AIN has been demonstrated to project to the DAO in a number of species (e.g., monkey: Kalil, '79; cat: Tolbert et al., '76; Dietrichs et al., '85; rat: Angaut and Cicirata, '82; Haroian, '82; Swenson and Castro, '83a,b; Billard et al., '89; oppossum: Martin et al., '76). In the cat, Courville et al. ('83) claimed that the rostral part of the AIN projects caudolaterally in the DAO, whereas its caudal part projects rostromedially. In the rat, the AIN often was not distinguished from the PIN and a more detailed topographical relationship between the AIN and the DAO was not yet reported. In our material a caudolateral to rostromedial gradient was observed corresponding to a mediolateral gradient in the DAO.
The dorsal fold of the DAO is not innervated from any of the cerebellar nuclei, but receives afferents from the lateral vestibular nucleus (see also Nelson and Mugnaini, '89).

\section{Conclusions}

The detailed topological relations of the connections between the central cerebellar nuclei and the inferior olive appear to be rather complex. Within some areas a noninversed mediolateral relationship exists (e.g., DLP and mediocaudal MAO), whereas other areas show an inversed mediolateral topology (e.g., AIN and DAO). Also, inversed (e.g., PIN-rostral MAO) as well as noninversed (DLH-DM) rostrocaudal relations were noted.

It is possible to simplify the observed relationships if one considers both the cerebellar nuclei as well as the inferior olive as continuous sheets of cells. The nucleo-olivary projection performs a simple topological transformation of one sheet onto the other as is schematized in Figure 11. Both sheets are folded, the primary fold in the olive is located between the VLPO and the DLPO; in the cerebellar nuclei between the ventromedial and dorsolateral LCN. The occurrence of reversed and nonreversed topological relations may be explained by the presence of secondary folds in both sheets, which are opposite in direction. In the case of the rat olive, the sheet starts laterally within the caudal MAO and continues medially until one arrives at the "beta" group. The rostral part of the "beta" group lies directly medial to the VLO; from here a continuation can be observed with the VLPO, the bend of the PO, the DLPO, and the DAO. Caudally, the DAO is continuous with the dorsal fold of the DAO, where the sheet ends medially. Since the DC was not labelled in any of our experiments, it was omitted in this scheme. However, it may be seen as an intermediate cell cluster between group "beta" and the VLO.

A similar continuity may be observed between the individual cell groups of the cerebellar nuclei. The sheet starts 
with the rostral MCN (projecting to the lateral parts of the caudal MAO), from where it continues dorsolaterally as the DLP (projecting to medial parts of the caudal MAO), bending caudally and ventrally as the caudal and lateral pole of the MCN (projecting to group "beta"). The ventrolateral MCN (at approximately level 6) is connected with the ventromedial, parvicellular part of the LCN (innervating the VLO). The nuclear sheet continues as the ventromedial leaf of the LCN (projecting to the VLPO). Via the ventrolateral and dorsolateral LCN (projecting to the bend of the PO and to the DLPO), one arrives at the DLH (projecting to the DM) and the lateral and medial AIN (the projection of the AIN to the DAO is essentially reversed). Ventrally, the medial AIN borders on the LVN (projecting to the dorsal fold of the DAO).

In this scheme the rostral MAO can be regarded as a rostral projection of the area between the medial part of the caudal MAO and the "beta" group or between the "beta" group and the VLO, whereas the PIN can be considered as a caudal expansion of an area between the lateral MCN and the ventral leaf of the LCN. Likewise, one can consider the DLH as a separate outgrowth between the dorsal LCN and lateral AIN, corresponding to a olivary DM group that may be considered as a medial bulge between DLPO and medial DAO, which happens to located adjacent to the VLPO. The DMCC is regarded as a part of the "beta" group since it is also innervated from the lateral MCN (though from more ventrolateral areas)

Species differences in nucleo-olivary projection may be explained by differences in the folding of the nuclear and olivary cell masses and/or by local hypertrophies.

Since there is abundant evidence that the nucleo-olivary and olivo-nuclear projections are, at least in part, reciprocal (Dietrichs and Walberg, '85, '86, '89; Dietrichs et al., '85; Billard et al., '89; Van der Want et al., '89), it is tempting to suggest that this reciprocity is also maintained when regarding the more detailed topological relationships.

\section{ACKNOWLEDGMENTS}

The authors thank Mr. Hans van der Burg for developing the iontophoresis device. Mr. Ed Dalm provided excellent surgical assistance. We are indebted to Ms. Erika Goedknegt and Mr. Rob Boer for technical aid, and to Ms. Paula van Alphen for photographic assistance.

\section{LTTERATURE CITED}

Achenbach, K.E., and D.C. Goodman (1968) Cerebellar projections to pons, medulla and spinal cord in the albino rat. Brain Behav. Evol. 1:43-57.

Angaut, P., and F. Cicirata (1982) Cerebello-olivary projections in the rat. An autoradiographic study. Brain Behav. Evol. 21:24-33.

Angaut, P., and C. Sotelo (1987) The dentato-olivary projection in the rat as a presumptive GABAergic link in olivo-cerebello-olivary loop. An ultrastructural study. Neurosci. Lett. 83:227-231.

Angaut, P., and C. Sotelo (1989) Synaptology of the cerebello-olivary pathway. Double labelling with anterograde axonal tracing and GABA immunocytochemistry in the rat. Brain Res. 479:361-365.

Arends, J.J.A., and J. Voogd (1989) Topographical aspects of the olivocerebellar system in the pigeon. In P. Strata (ed): The Olivocerebellar System in Motor Control. Exp. Brain Res. Series 17. Berlin: Springer-Verlag, pp. $52-57$.

Asanuma, C., W.T. Thach, and E.G. Jones (1983) Brainstem and spinal projections of the deep cerebellar nuclei in the monkey, with observations on the brainstem projections of the dorsal column nuclei. Brain Res. Rev. 5:299-322.
Azizi, S.A., and D.J. Woodward (1987) Inferior olivary nuclear complex of the rat: Morphology and comments on principles of organization within the olivocerebellar system. J. Comp. Neurol. 263:467-484.

Batton, R.R., A. Jayaraman, D. Ruggiero, and M.B. Carpenter (1977) Fastigial efferent projections in the monkey: An autoradiographic study. J. Comp. Neurol. 174:281-306.

Beitz, A.J. (1976) The topographical organization of the olivodentate and dentato-olivary pathways in the cat. Brain Res. 115:311-317.

Bernard, J.-F. (1987) Topographical organization of olivocerebellar and corticonuclear connections in the rat-An WGA-HRP study: I. Lobules IX, $\mathrm{X}$ and the flocculus. J. Comp. Neurol. 263:241-258.

Billard, J.M., C. Batini, C. Buisseret-Delmas, and H. Daniel (1989) The inferior olive innervation from the cerebellar and lateral vestibular nuclei: Evidence for a longitudinal zonal segregation of the cortico-nucleoolivary connection in the rat. In P. Strata (ed): The Olivocerebellar System in Motor Control. Exp. Brain Res. Series 17. Berlin: SpringerVerlag, pp. 117-120.

Brodal, A. (1940) Experimentelle Untersuchungen uber die olivocerebellare Lokalisation. Z. Ges. Neurol. Pshyiatr. 169:1-153

Brodal, A., and K. Kawamura (1980) Olivocerebellar projection: A review. Adv. Anat. Embryol. Cell Biol. 64A:1-140.

Brown, J.T., V. Chan-Palay, and S.L. Palay (1977) A study of afferent input to the inferior olivary complex in the rat by retrograde axonal transport of horseradish peroxidase. J. Comp. Neurol. 176:1-22.

Buisseret-Delmas, C., and C. Batini (1978) Topology of the pathways to the inferior olive: An HRP study in the cat. Neurosci. Lett. 10:207-214.

Buisseret-Delmas, C., C. Batini, C. Compoint, $H$. Daniel, and D. Menetrey (1989) The Gabaergic neurones of the cerebellar nuclei: Projection to the caudal inferior olive and to the bulbar reticular formation. In P. Strata (ed): The Olivocerebellar System in Motor Control. Exp. Brain Res. Series 17. Berlin: Springer-Verlag, pp. 108-110.

Cajal, S. Ramón y (1903) La dobla via descendente nacida del pedunculo cerebeloso superior. Trab. Lab. Ins. Biol. Univ. Madrid 2:23-29.

Cajal, S. Ramón y (1911) Histologie des système nerveux de l'homme et des vertébrés. Paris: Maloine.

Chan-Palay, V. (1977) Cerebellar dentate nucleus. Organization, cytology and transmitters. Berlin: Springer-Verlag.

Courville, J., F. Faraco-Cantin, and A. Legendre (1983) Detailed organization of cerebello-olivary projections in the cat. An autoradiographic study. Arch. Ital. Biol. 121:219-236.

De Zeeuw, C.I., J.C. Holstege, T.J.H. Ruigrok, and J. Voogd (1989a) The cerebellar, mesodiencephalic and GABAergic innervation of the glomeruli in the cat inferior olive. A comparison at the ultrastructural level. In P. Strata (ed): The Olivocerebellar System in Motor Control. Exp. Brain Res. Series 17. Berlin: Springer-Verlag, pp. 111-116.

De Zeeuw, C.I., J.C. Holstege, T.J.H. Ruigrok, and J. Voogd (1989b) Ultrastructural study of the GABAergic, cerebellar and mesodiencephalic innervation of the cat medial accessory olive: Anterograde tracing combined with immunocytochemistry. J. Comp. Neurol. 284:12-35.

De Zeeuw, C.I., J.C. Holstege, T.J.H. Ruigrok, and J. Voogd (1990) Mesodiencephalic and cerebellar terminals terminate upon the same dendritic spines within the glomeruli of the eat and rat inferior olive: An ultrastructural study using a combination of $3 \mathrm{H}$-leucine and WGA-HRP anterograde tracing. Neurosci. 34: 645-655.

De Zeeuw, C.I., J.C. Holstege, F. Calkoen, T.J.H. Ruigrok, and J. Voogd (1988) A new combination of WGA-HRP anterograde tracing and GABA-immunocytochemistry applied to afferents of the cat inferior olive at the ultrastructural level. Brain Res. 447:369-375.

Dietrichs, E., and F. Walberg (1985) The cerebellar nucleo-olivary and olivo-cerebellar nuclear projections in cat as studied with anterograde and retrograde transport in the same animal after implantations of crystalline WGA-HRP. II. The fastigial nucleus. Anat. Embryol. 173:253261.

Dietrichs, E., and F. Walberg (1986) The cerebellar nucleo-olivary and olivo-cerebellar nuclear projections in cat as studied with anterograde and retrograde transport in the same animal after implantations of crystalline WGA-HRP. III. The interposed nuclei. Brain Res. 373:373383.

Dietrichs, E., and F. Walberg (1989) Direct bidirectional connections between the inferior olive and the cerebellar nuclei. In P. Strata (ed): The Olivocerebellar System in Motor Control. Exp. Brain Res. Series 17 Berlin: Springer-Verlag, pp. 61-81.

Dietrichs, E., F. Walberg, and T. Nordby (1985) The cerebellar nucleoolivary and olivo-cerebellar nuclear projections in cat as studied with anterograde and retrograde transport in the same animal after implanta- 
tions of crystalline WGA-HRP. I. The dentate nucleus. Neurosci. Res. 3:52-70.

Dom, R., J.S. King, and G.F. Martin (1973) Evidence for two direct cerebello-olivary connections. Brain Res. 57:498-501.

Faull, R.L.M. (1978) The cerebellofugal projections in the brachium conjunctivum of the rat. II. The ipsilateral and contralateral descending pathways. J. Comp. Neurol. 178:519-536.

Gerfen, C.R., and P.F. Sawchencko (1984) An anterograde neuroanatomical tracing method that shows detailed morphology of neurons, their axons and terminals: Immunohistochemical localization of an axonally trans. ported plant lectin, Phaseolus vulgaris-leucoagglutinin (PHA-L). Brain Res. 290:219-238.

Goodman, D.C., R.E. Hallett, and R.B. Welch (1963) Patterns of localization in the cerebellar corticonuclear projections of the albino rat. J. Comp. Neurol. 121:51-67.

Graybiel, A.M., H.J.W. Nauta, R.J. Lasek, and W.J.H. Nauta (1973) A cerebello-olivary pathway in the cat: An experimental study using autoradiographic tracing techniques. Brain Res. 58:205-211.

Groenewegen, H.J., and J. Voogd (1977) The parasagittal zonation within the olivo-cerebellar projection. I. Climbing fiber distribution in the vermis of the cat cerebellum. J. Comp. Neurol. 174:417-488.

Groenewegen, H.J., J. Voogd, and S.L. Freedman (1979) The parasagittal zonation within the olivo-cerebellar projection. II. Climbing fiber distri bution in the intermediate and hemispheric parts of the cat cerebellum. J. Comp. Neurol. 183:551-602.

Gwyn, D.G., G.P. Nicholson, and B.A. Flumerfelt (1977) The inferior olivary nucleus of the rat: A light and electron microscopic study. J. Comp. Neurol. 174:489-520.

Haroian, A.J. (1982) Cerebello-olivary projections in the rat: An autoradiographic study. Brain Res. 235:125-130.

Haroian, A.J., L.C. Massopust, and P.A. Young (1981) Cerebellothalamic projections in the rat: An autoradiographic and degeneration study. J. Comp. Neurol. 197:217-236.

Huerta, M.F., A. Frankfurter, and J.K. Harting (1983) Studies of the principal sensory and spinal trigeminal nuclei of the rat: Projections to the superior colliculus, inferior olive, and cerebellum. J. Comp. Neurol. 220:147-167.

Ikeda, Y., H. Noda, and S. Sugita (1989) Olivocerebellar and cerebello-olivary connections of the oculomotor region of the fastigial nucleus in the macaque monkey. J. Comp. Neurol. 284:463-488.

Kalil, K. (1979) Projections of the cerebellar and the dorsal column nuclei upon the inferior olive in the rhesus monkey: An autoradiographic study. J. Comp. Neurol. 188:43-62.

Korneliussen, H.K. (1968) On the morphology and subdivision of the cerebellar nuclei of the rat. J. Hirnforsch. 10:109-122.

Lapresle, J., and M. Ben Hamida (1970) The dentato-olivary pathway. Somatotopic relationship between the dentate nucleus and the contralateral inferior olive. Arch. Neurol. 22:135-143.

Martin, G.F., C.K. Henkel, and J.S. King (1976) Cerebello-olivary fibers: Their origin, course and distribution in the North American opossum. Exp. Brain Res. 24:219-236.

Mehler, W.R. (1967) Double descending pathways originating from the superior cerebellar peduncle: An example of neural species differences. Anat. Rec. 157:374

Mehler, W.R. (1969) Some neurological species differences-a posteriori. Ann. N.Y. Acad. Sci. 167:424-468.

Mugnaini, E., and W.H. Oertel (1981) Distribution of GAD-positive neurons in the rat cerebellar nuclei. Soc. Neurosci. Abstr. 11:122.

Mugnaini, E., and W.H. Oertel (1985) An atlas of the distribution of GABAergic neurons and terminals in the rat $\mathrm{CNS}$ as revealed by GAD immunocytochemistry. In A. Bjorklund and T. Hokfelt (eds): Handbook of Chemical Neuroanatomy, vol. 4: GABA and Neuropeptides in the CNS, Part 1. New York: Elsevier, pp. 436-608.

Nelson, B., and E. Mugnaini (1985) Loss of GABAergic nerve terminals in the inferior olive of cerebellectomized rats. Soc. Neurosci. Abstr. 11:182.

Nelson, B.J., and E. Mugnaini (1988) The rat inferior olive as seen with immunostaining for glutamate decarboxylase. Anat. Embryol. 179:109 127.

Nelson, B., and E. Mugnaini (1989) Origins of GABAergic inputs to the inferior olive. In P. Strata (ed): The Olivocerebellar System in Motor Control. Exp. Brain Res. Series 17. Berlin: Springer-Verlag, pp. 86-107.

Nelson, B., N.H. Barmack, and E. Mugnaini (1984) A GABAergic cerebelloolivary projection in the rat. Soc. Neurosci. Abstr. 10:539.

Paxinos, G., and C. Watson (1986) The Rat Brain in Stereotaxic Coordinates. Sydney: Academic Press.

Ruigrok, T.J.H., and J. Voogd (1988a) Evidence for cerebello-midbrainolivary circuits in rat using PHA-L anterograde, and gold labeled WGA-BSA retrograde tracing. Abstr. 11th Ann. Meeting ENA (Suppl. Eur. J. Neurosci.), p. 24.

Ruigrok, T.J.H., and J. Voogd (1988b) Olivary projections to the flocculus in the rat; an anterograde PHA-L study. Abstr. 11th Ann Meeting ENA (Suppl. Eur. J. Neurosci.), p. 24.

Sotelo, C., T. Gotow, and M. Wassef (1986) Localization of glutamic-aciddecarboxylase-immunoreactive axon terminals in the inferior olive of the rat, with special emphasis on anatomical relations between GABAergic synapses and dendrodendritic gap junctions. J. Comp. Neurol. 252:3250 .

Sugimoto, T., N. Mizuno, S. Nomura, and Y. Nakamura (1980) Fastigioolivary fibers in the cat as revealed by the autoradiographic tracing method. Brain Res. 199:443-446.

Swenson, R.S., and A.J. Castro (1983a) The afferent connections of the inferior olivary complex in rats. An anterograde study using autoradiographic and axonal degeneration techniques. Neurosci. 8:259-275.

Swenson, R.S., and A.J. Castro (1983b) The afferent connections of the inferior olivary complex in rats: A study using the retrograde transport of horseradish peroxidase. Am. J. Anat. 166:326-341.

Tolbert, D.L., L.C. Massopust, M.G. Murphy, and P.A. Young (1976) The anatomical organization of the cerebello-olivary projection in the cat. J. Comp. Neurol. 170:525-544.

Van der Want, J.J.L., L. Wiklund, M. Guegan, T. Ruigrok, and J. Voogd (1989) Anterograde tracing of the rat olivocerebellar system with Phaseolus vulgaris leucoagglutinin (PHA-L). Demonstration of climbing fiber collateral innervation of the cerebellar nuclei. J. Comp. Neurol. 288: $1-18$.

Voogd, J., Gerrits, N.M., and E. Marani (1985) Cerebellum. In G. Paxinos (ed): The Rat Nervous System, Vol. 2. Sydney, Academic Press, pp 251-291.

Whitworth, R.H., and D.E. Haines (1986) On the question of nomenclature of homologous subdivisions of the inferior olivary complex. Arch. Ital. Biol. 124:271-317.

Woodson, W, and P. Angaut (1984) The ipsilateral descending limb of the brachium conjunctivum: An autoradiographic and HRP study in rats. Neurosci. Lett. Suppl. 18, S 58.

Wouterlood, F.G., and H.J. Groenewegen (1985) Neuroanatomical tracing by use of Phaseolus vulgaris-leucoagglutinin (PHA-L): Electron microscopy of PHA-L-filled neuronal somata, dendrites, axons and axon terminals. Brain Res. 326:188-191. 